\title{
Formation mechanisms of ringwoodite: clues from the Martian meteorite Northwest Africa 8705
}

\author{
Ting Zhang ${ }^{1,2}$, Sen Hu${ }^{1}$, Nian Wang ${ }^{1,2}$, Yangting Lin ${ }^{1 *} \mathbb{0}$, Lixin Gu ${ }^{1,3}$, Xu Tang $^{1,3}$, Xinyu Zou ${ }^{4}$ and \\ Mingming Zhang ${ }^{1}$
}

\begin{abstract}
Ringwoodite and wadsleyite are the high-pressure polymorphs of olivine, which are common in shocked meteorites. They are the major constituent minerals in the terrestrial mantle. NWA 8705, an olivine-phyric shergottite, was heavily shocked, producing shock-induced melt veins and pockets associated with four occurrences of ringwoodite: (1) the lamellae intergrown with the host olivine adjacent to a shock-induced melt pocket; (2) polycrystalline assemblages preserving the shapes and compositions of the pre-existing olivine within a shock-induced melt vein $(60 \mu \mathrm{m}$ in width); (3) the rod-like grains coexisting with wadsleyite and clinopyroxene within a shock-induced melt vein; (4) the microlite clusters embedded in silicate glass within a very thin shock-induced melt vein ( $20 \mu \mathrm{m}$ in width). The first two occurrences of ringwoodite likely formed via solid-state transformation from olivine, supported by their morphological features and homogeneous compositions (Mg\# 64-62) similar to the host olivine (Mg\# 66-64). The third occurrence of ringwoodite might fractionally crystallize from the shock-induced melt, based on its heterogeneous and more FeO-enriched compositions (Mg\# 76-51) than those of the coexisting wadsleyite (Mg\# 77-67) and the host olivine (Mg\# 66-64) of this meteorite. The coexistence of ringwoodite, wadsleyite, and clinopyroxene suggests a postshock pressure of $14-16 \mathrm{GPa}$ and a temperature of $1650-1750^{\circ} \mathrm{C}$. The fourth occurrence of ringwoodite with compositional variation (Mg\# 72-58) likely crystallized from melt at 16-18 GPa and $1750-1850^{\circ} \mathrm{C}$. The presence of the four occurrences of ringwoodite was probably due to their very fast cooling rates in and/or adjacent to the thin shockinduced melt veins and small pockets. In addition, the higher Fa-contents of the host olivine $\left(\mathrm{Fa}_{35-39}\right)$ in NWA 8705 than those in ordinary chondrites $\left(\mathrm{Fa}_{16-32}\right)$ makes the olivine-ringwoodite transformation prolong to a lower pressure.
\end{abstract}

Keywords: Martian meteorite, Shock metamorphism, Ringwoodite, High-pressure phase transformation, Shockinduced melt

\section{Introduction}

Meteorites commonly experienced various degrees of shock metamorphism, and some of them contain shockinduced melts and numerous high-pressure minerals (e.g., Stöffler and Keil 1991; Binns et al. 1969; Gillet et al. 2000; Xie et al. 2002; Langenhorst and Poirier 2000;

\footnotetext{
*Correspondence: linyt@mail.iggcas.ac.cn

${ }^{1}$ Key Laboratory of Earth and Planetary Physics, Institute of Geology and Geophysics, Chinese Academy of Sciences, Beijing 100029, China Full list of author information is available at the end of the article
}

Tschauner, 2014; Beck et al. 2004; Tomioka and Miyahara 2017; and references therein). The high-pressure polymorphs of olivine $\left[(\mathrm{Mg}, \mathrm{Fe})_{2} \mathrm{SiO}_{4}\right]$, ringwoodite $(\gamma$ - $(\mathrm{Mg}$, $\left.\mathrm{Fe})_{2} \mathrm{SiO}_{4}\right)$ and wadsleyite $\left(\beta-(\mathrm{Mg}, \mathrm{Fe})_{2} \mathrm{SiO}_{4}\right)$, are of particularly important, because they are the major constituents of the Earth's mantle transition zone (Ohtani and Sakai 2008). Previous studies of ringwoodite/wadsleyite in meteorites suggested that they were mainly produced via solid-state transformation from olivine and crystallization from shock-induced melts (Miyahara et al. 2008; Walton and McCarthy 2017; Chen et al. 2004). Studying 
the transformation mechanisms of ringwoodite is not only helpful to understand the Earth's interior dynamic process (Kerschhofer et al. 1996; Mohiuddin et al. 2020), but also important to determine the post-shock $\mathrm{P}-\mathrm{T}-\mathrm{t}$ conditions and the related sizes of the impactors (e.g., $\mathrm{Hu}$ and Sharp 2016; Ozawa et al. 2010; Sharp and De Carli 2006; Ohtani et al. 2004; Beck et al. 2005; Fritz et al. 2005).

Three occurrences of ringwoodite in heavily shocked meteorites have been reported, i.e., fine-grained ringwoodite in shock-induced melt vein matrix (Xie et al. 2006a; Miyahara et al. 2008), lamellar ringwoodite intergrown with the host olivine (Miyahara et al. 2010; Greshake et al. 2013; Chen et al. 2006), and polycrystalline ringwoodite assemblages with pseudomorph of olivine (Ozawa et al. 2010; Ohtani et al. 2004; Chen et al. 1996). The first occurrence of ringwoodite crystallized from shock-induced melt (Xie et al. 2006a; Fritz and Greshake 2009), whereas the other two occurrences were probably produced via solid-state phase transformation from olivine, including homogeneous intracrystalline nucleation throughout the olivine (Chen et al. 1996), heterogeneous intracrystalline nucleation at defect sites (fractures and stacking faults) of the olivine (Kerschhofer et al. 1996, 2000; Miyahara et al. 2010; Chen et al. 2006, 2007), and grain boundary nucleation and growth mechanism (Liu et al. 1998; Kerschhofer et al. 1998). In some cases, the ringwoodite lamellae have a crystallographic relationship of $\{111\}_{\mathrm{Rwt}} / /(100)_{\mathrm{Ol}}$ with the host olivine, indicating a coherent nucleation process of ringwoodite (Miyahara et al. 2010, 2016). In terms of chemical compositions, some ringwoodite lamellae and polycrystalline grains have almost identical compositions to the original olivine, indicating an interface-controlled growth process (Xie and Sharp 2007; Mosenfelder et al. 2001; Ohtani et al. 2004; Chen et al. 1996) in which the growth of ringwoodite is controlled by the rate of short range diffusion across the interface between the two phases (Sharp and De Carli 2006). Some polycrystalline ringwoodite rims surrounding the olivine show a $\mathrm{Fe}-\mathrm{Mg}$ diffusion-controlled growth process (Walton and McCarthy 2017; Yin et al. 2018; Pittarello et al. 2015) with Fe preferentially partitioned to ringwoodite, leading to a higher FeO content of ringwoodite compared with the residual olivine.

Many high-pressure minerals have been identified within and adjacent to shock-induced melt veins and pockets in Martian basaltic meteorites as Tomioka and Miyahara (2017) have summarized. Of these high-pressure polymorphs, ringwoodite was reported in Tissint, EETA 79001, DaG 670, NWA 8159, NWA 7755, Chassigny, RBT 04261, NWA 1068, and LAR 12095 (Walton 2013; Ma et al. 2016; Greshake et al. 2013; Fritz and Greshake 2009; Wang et al. 2017; Sharp et al. 2019;
Takenouchi et al. 2018). It occurs as lamellae and polycrystalline grains in the host olivine (Walton 2013; Ma et al. 2016; Greshake et al. 2013; Sharp et al. 2019; Walton et al. 2014; Takenouchi et al. 2018), or as submicronsized grains in the melt veins (Walton, 2013; Fritz and Greshake 2009; Sharp et al. 2019). Discovery of more occurrences of ringwoodite would be helpful to understand its formation mechanisms and to clarify impact history of the Martian meteorites (Wang et al. 2017; Miyahara et al. 2016).

NWA 8705 is a Martian olivine-phyric basaltic meteorite found recently (Irving et al. 2017). It experienced strong shock metamorphism with the presence of shockinduced melt veins and pockets, making it ideal to study the phase transformation of ringwoodite and wadsleyite from olivine in Martian meteorites. In this study, we found four occurrences of ringwoodite in NWA 8705, and conducted a comprehensive petrographic, mineralchemical and crystallographic analyses to clarify their formation mechanisms, constrain the post-shock $\mathrm{P}-\mathrm{T}$ conditions, and to shed light on the impact history of the NWA 8705.

\section{Sample and methods}

The Martian meteorite NWA 8705 (6.2 g) was found in Morocco in 2014 and classified as an olivine-phyric shergottite (Irving et al. 2017). One polished section was used in this study, with a surface of $\sim 1 \times 0.7 \mathrm{~cm}^{2}$.

The section was observed with a field emission scanning electron microscope (FE-SEM) of FEI Nava NanoSEM 450 FE-SEM equipped with an Oxford X-MAXN $80 \mathrm{~mm}^{2}$ energy dispersive spectrometer (EDS) at the Institute of Geology and Geophysics, Chinese Academy of Sciences (IGGCAS). The FE-SEM was operated under a condition of $15 \mathrm{kV}$ accelerating voltage and 1.6-3.2 $\mathrm{nA}$ beam current.

Raman spectra were acquired using a confocal Raman microscope (LabRAM HR Evolution system) equipped with $1800 \mathrm{~g} / \mathrm{mm}$ gratings and a liquid nitrogen-cooled CCD detector, operating with an Nd: YAG laser of $532 \mathrm{~nm}$ wavelength at the National Astronomical Observatory, Chinese Academy of Sciences (NAOCAS). The laser power was $\sim 3.7 \mathrm{~mW}$, and the spatial resolution was $\sim 1 \mu \mathrm{m}$. The spectrum was calibrated with the peak of the silicon standard at $520.7 \pm 1 \mathrm{~cm}^{-1}$, and each spectrum was integrated twice for $30 \mathrm{~s}$ per time from 50 to $1500 \mathrm{~cm}^{-1}$.

Quantitative analysis of minerals was conducted with a JEOL JXA-8100 electron probe microanalyzer (EPMA) at IGGCAS. An accelerating voltage of $15 \mathrm{kV}$ and a beam current of $20 \mathrm{nA}$ were used for all analyses with a beam diameter ranging from 1 to $5 \mu \mathrm{m}$. Data were corrected using a modified ZAF correction procedure. Synthetic 
and natural minerals were used as the calibration standards: hematite for Fe, synthetic rutile for $\mathrm{Ti}, \mathrm{Cr}_{2} \mathrm{O}_{3}$ for $\mathrm{Cr}$, San Carlos olivine for $\mathrm{Mg}$, diopside for $\mathrm{Si}$ and $\mathrm{Ca}$, rhodonite for $\mathrm{Mn}$, apatite for $\mathrm{P}$, nickel oxide for $\mathrm{Ni}$, albite for $\mathrm{Na}$ and $\mathrm{Al}$, and orthoclase for $\mathrm{K}$. The detection limits are $0.01 \mathrm{wt} \%$ for $\mathrm{K}_{2} \mathrm{O}$ and $\mathrm{Al}_{2} \mathrm{O}_{3}, 0.02 \mathrm{wt} \%$ for $\mathrm{MgO}, \mathrm{Cr}_{2} \mathrm{O}_{3}$, $\mathrm{MnO}, \mathrm{TiO}_{2}, \mathrm{SiO}_{2}, \mathrm{CaO}$, and $\mathrm{Na}_{2} \mathrm{O}, 0.03 \mathrm{wt} \%$ for $\mathrm{FeO}$ and $\mathrm{NiO}, 0.04 \mathrm{wt} \%$ for $\mathrm{P}_{2} \mathrm{O}_{5}$.

Ultra-thin $\left(\sim 100 \mathrm{~nm} ; \sim 10 \times 3 \mu \mathrm{m}^{2}\right.$ in area) regions of interest on the polished meteorite section were prepared using a focused ion beam (FIB) of a Zeiss Auriga Compact dual-beam instrument equipped with an Omniprobe Auto Probe 200 micromanipulator at IGGCAS. $\mathrm{A} \mathrm{Ga}^{+}$beam current of $200 \mathrm{pA}(30 \mathrm{kV})$ and a $50 \mathrm{pA}$ $(5 \mathrm{kV})$ were applied for final thinning and polishing, respectively. The FIB slices were then analyzed using a transmission electron microscope (TEM) of JEM-2100 equipped with an EDS operated at $200 \mathrm{kV}$ at IGGCAS. The microstructures were studied using the high-resolution TEM imaging (HRTEM) and the selected area electron diffraction (SAED) followed the methods described by Gu et al. (2022) and Tang et al. (2020). Elemental mapping was performed using a FEI Tecnai F30 type of highangle annular dark-field scanning TEM (HAADF-TEM) equipped with four windowless X-ray detectors at $300 \mathrm{kV}$ at the Peking University.

\section{Results}

\section{Petrography and mineral chemistry}

NWA 8705 is an olivine-phyric shergottite, consisting of large (up to $2 \mathrm{~mm}$ ) olivine phenocrysts embedded in the fine-grained groundmass (Fig. 1). The modal mineral abundance is $15 \mathrm{vol} \%$ olivine, $55 \mathrm{vol} \%$ pigeonite, 5.8 vol\% augite and 20.5 vol\% plagioclase (maskelynite), and 3.7 vol\% accessory phases including chromite, ilmenite, sulfide, and phosphate. The olivine and pyroxene grains are highly fractured (Fig. 1a), whereas plagioclase grains have smooth surfaces with few cleavages (Fig. 1b, c). The Raman spectra indicate that many plagioclase grains have been converted into maskelynite (Fig. 1; Figure S1, \#1, see Additional file 1 for details). Several shock-induced melt veins $(<60 \mu \mathrm{m}$ in width $)$ and pockets $\left(<400 \times 250 \mu \mathrm{m}^{2}\right.$ in area) were found in the section. Ringwoodite and/ or wadsleyite were observed within or adjacent to the shock-induced melt veins and pockets (Figs. 2, 4 and 7). The detailed occurrences of ringwoodite and wadsleyite are depicted in the following subsection.

Most of olivine gains ( $<1 \mathrm{~mm}$ in length) have homogeneous compositions, with a range of the $\mathrm{Fa}$-content of 35-39 $(\mathrm{Fa}=$ molar $100 \times \mathrm{Fe} /(\mathrm{Fe}+\mathrm{Mg}))$ among grains. A few larger olivine crystals ( $\sim 2 \mathrm{~mm}$ in length) are chemically zoned, with the Fa-content increasing from 29.4 in the cores to 37 at the rims (Table S1, see Additional file 2 for details). $\mathrm{MnO}$ and $\mathrm{CaO}$ contents in olivine range from 0.55 to $0.68 \mathrm{wt} \%$ and from 0.14 to $0.38 \mathrm{wt} \%$, respectively. Pigeonite occurs as elongated prismatic or oval grains with a length of $0.2-1.0 \mathrm{~mm}$. Individual pigeonite grains also show the core-rim zonings, with the Fs-contents $(\mathrm{Fs}=$ molar $100 \times \mathrm{Fe} /(\mathrm{Fe}+\mathrm{Mg}+\mathrm{Ca}))$ increasing from $23.6 \mathrm{~mol} \%$ in the cores to $31.3 \mathrm{~mol} \%$ at the rims. The overall chemical compositions of pigeonite are in a range of $\mathrm{Fs}_{22.8-33.1} \mathrm{En}_{59.7-69.6} \mathrm{Wo}_{6.6-12.6}$. The minor elements are $\mathrm{Al}_{2} \mathrm{O}_{3}(0.4-1.4 \mathrm{wt} \%), \mathrm{Cr}_{2} \mathrm{O}_{3}(0.2-0.9 \mathrm{wt} \%)$ and $\mathrm{TiO}_{2}(0.03-0.8 \mathrm{wt} \%)$. Augite typically occurs either at the margins of pigeonite (Fig. 1b, c) or as separate grains with sizes of $50-100 \mu \mathrm{m}$. The individual augite grains are relatively homogeneous in chemical composition, while showing significant variation among different grains $\left(\mathrm{Fs}_{15.2-29.1} \mathrm{En}_{44.5-58.9} \mathrm{Wo}_{18.3-38.6}\right)$. The minor elements are $\mathrm{Al}_{2} \mathrm{O}_{3}$ (1.4-2.3 wt\%), $\mathrm{Cr}_{2} \mathrm{O}_{3}$ (0.1-1.0 wt\%) and $\mathrm{TiO}_{2}(0.2-1.0 \mathrm{wt} \%)$. Maskelynite is subhedral lathshaped $(0.8-1.3 \mathrm{~mm}$ in length) and interstitial to pyroxene and olivine. The composition of the maskelynite is $\mathrm{An}_{50-67} \mathrm{Ab}_{49-33} \mathrm{Or}_{0-1}$, while a few grains display zoning features, e.g., with $\mathrm{An}_{61} \mathrm{Ab}_{38} \mathrm{Or}_{1}$ in the cores to $\mathrm{An}_{52} \mathrm{Ab}_{47} \mathrm{Or}_{1}$ at the rims. The representative chemical compositions of these minerals are listed in Table S1 and S2 (see Additional file 2 for details).

\section{Four occurrences of ringwoodite Ringwoodite lamellae}

Olivine grains (Fig. 2a, b) that are located within and/ or adjacent to the shock-induced melts often appear heterogeneous in contrast in BSE images, with one to three sets of brighter lamellae $(<3 \mu \mathrm{m}$ in width) intergrown with the host olivine (Fig. 2c). It is noticed that the lamellae also develop at the olivine margin in contact with melt and disappear away from it (Fig. 2d). Laser Raman analysis confirms that these lamellae are ringwoodite, with the diagnostic peaks at 792$795 \mathrm{~cm}^{-1}$ and $842 \mathrm{~cm}^{-1}$ (R2 and R3 in Fig. 3a). In addition, additional peaks at $213-217 \mathrm{~cm}^{-1}$ and $586 \mathrm{~cm}^{-1}$ correspond to ringwoodite (Walton and McCarthy 2017; Acosta-Maeda et al. 2013). The peak at $697 \mathrm{~cm}^{-1}$ may also be derived from ringwoodite, which is similar to the peak at $692 \mathrm{~cm}^{-1}$ of ringwoodite in LAR 12095 (Takenouchi et al. 2018). Raman analyses without significant peaks indicate the presence of olivine glass (R4 in Fig. 3a; $\mathrm{Fa}_{35.9}$, Additional file 2: Table S3) adjacent to the melt (Fig. 2c). The texture of olivine glass is similar to the glass depicted in NWA 4468 (Boonsue and Spray 2012). The Mg\#-numbers of the ringwoodite lamellae $(\mathrm{Mg} \#$ 64.2-62.7; $\mathrm{Mg} \#=100 * \mathrm{Mg} /(\mathrm{Mg}+\mathrm{Fe}))$ are very similar to those of the host olivine (Mg\# 65.4-64; Table S3, see Additional file 2 for details). The TEM observations of the FIB section (FIB-slice 

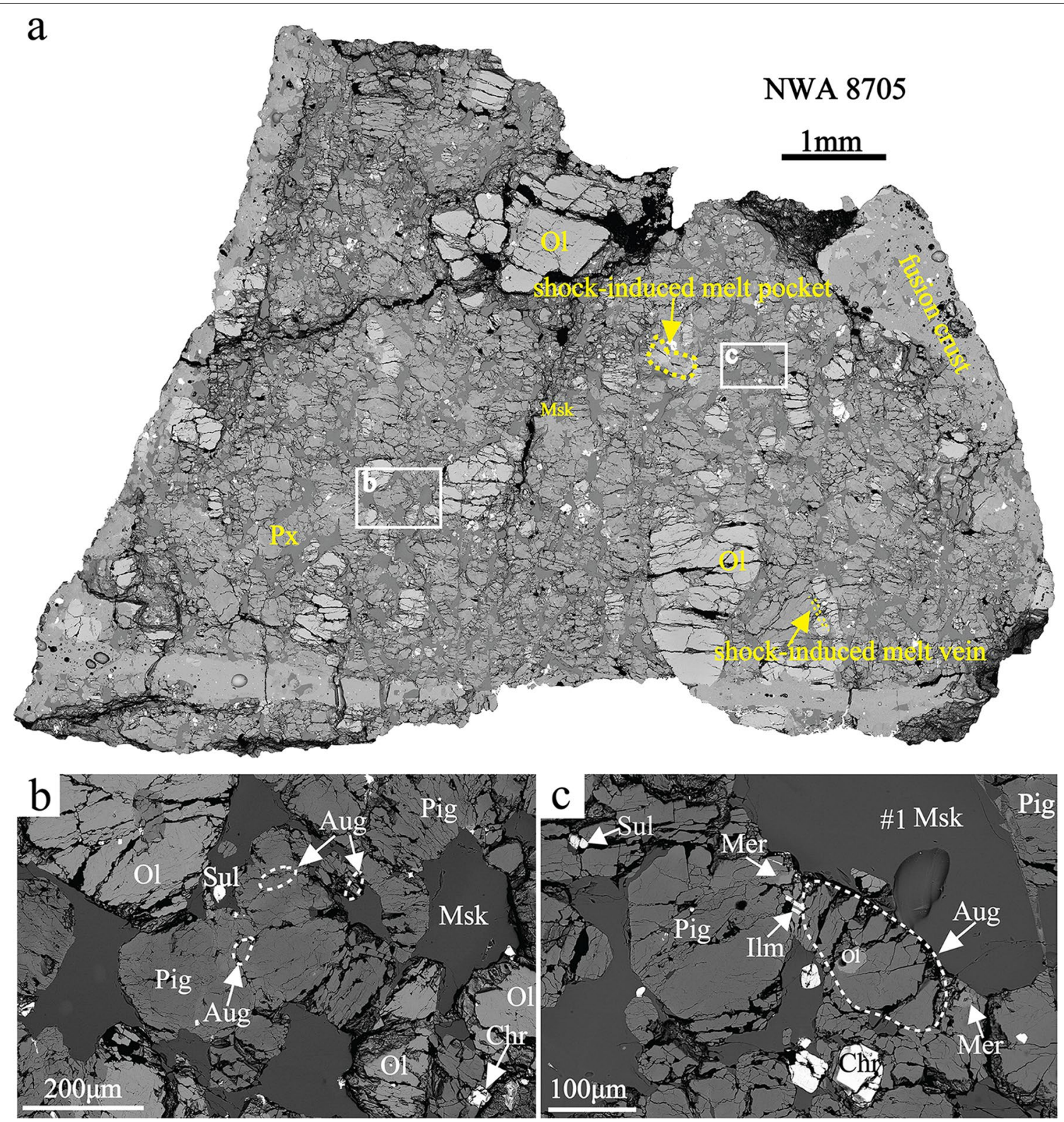

Fig. 1 BSE images of NWA 8705. a BSE mosaic map of NWA 8705. Shock-induced melt veins and pockets are indicated by yellow dotted lines and arrows. b, c are the enlarged BSE images of NWA 8705 marked as white boxes in a. Augite (Aug) occurs as the margin of pigeonite (Pig) or as individual grains (outlined by dotted lines). Note abundant fractures of olivine and pyroxene, in comparison with the smooth surface of maskelynite. \#1 is the position of a Raman analysis of maskelynite (Msk). Other abbreviations: Rwt ringwoodite, Chr chromite, Mer merrillite, IIm ilmenite, Sul sulfide

\#1) prepared from the region marked in Fig. 2c show ringwoodite platelets with width ranging from $\sim 10$ to $\sim 100 \mathrm{~nm}$ (Fig. 2e, f). The selected area electron diffraction (SAED) patterns show the crystallographic orientation between ringwoodite lamellae and the host olivine: $\{111\}_{\text {Rwt }} / /(100)_{\mathrm{Ol}}$ (Fig. 2f). 

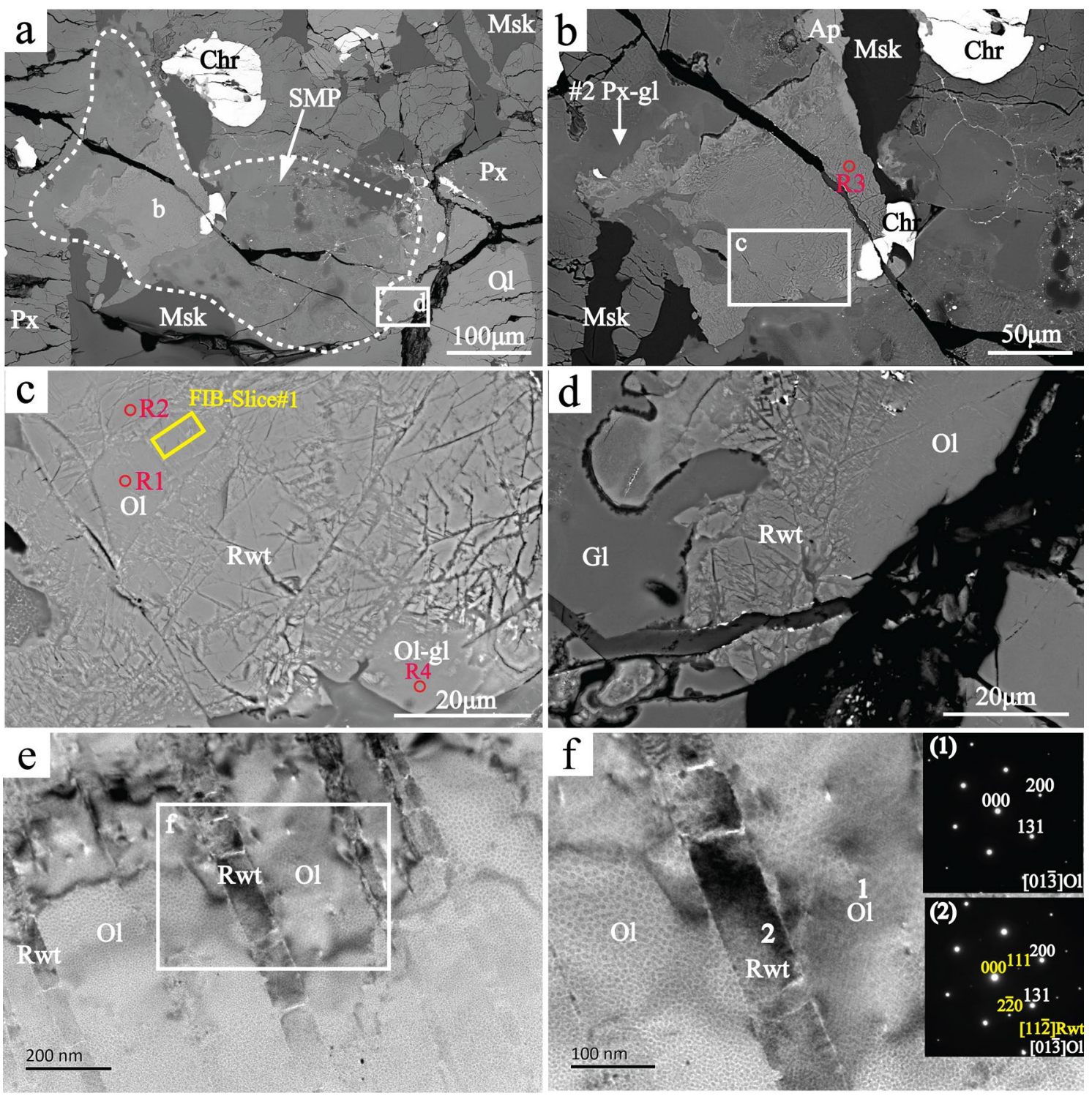

Fig. 2 BSE images of ringwoodite lamellae. a shock-induced melt pocket (SMP) outlined by the dotted line. The grain labeled "b" and the white box labeled "d" are shown in $\mathbf{b}$ and $\mathbf{d}$, respectively. $\mathbf{b}$ High magnification image of grain "b", showing significant heterogeneity. Raman analyses were conducted on the adjacent pyroxene (\#2 px-gl) and on the lamellae (R3). $\mathbf{c}$ Enlarged image of white box "c" in $\mathbf{b}$ reveals ringwoodite (Rwt) lamellae intergrown with the host olivine (OI). R1, R2, and R4 are the analyses positions of Raman spectra. The yellow box indicates the position of FIB-slice \#1. d Enlarged image of white box " $\mathrm{d}$ " in a shows that the olivine in contact with the glass phase (Gl) has been transformed into ringwoodite lamellae. e Bright-field (BF) TEM image from the FIB-slice \#1. The lamellae parallel to each other. $\mathbf{f}$ Enlarged BF-TEM image of the white box "f" in $\mathbf{e}$. The SAED pattern of region 1 shows olivine viewed along the crystal zone axis [01 $\overline{3}]$. The SAED pattern of region 2 shows that crystallographic relationship $\{111\}_{\mathrm{Rwt}} / /(100)_{\mathrm{Ol}}$ exist. SMP shock-induced melt pocket, Ap apatite; others are the same as above

\section{Polycrystalline ringwoodite aggregates with pseudomorph of pre-existing olivine fragment}

The olivine fragments within the shock-induced melt vein (60 $\mu \mathrm{m}$ in width) have been transformed to polycrystalline ringwoodite aggregates (Fig. $4 \mathrm{~b}, \mathrm{c}$ ). These fragments (3-20 $\mu \mathrm{m}$ in width) preserve pseudomorphs of olivine, but appear cloudy under high magnification BSE images
(Fig. 4b, c, and f), distinguished from the homogeneous surface of the host olivine away from the melts. Raman spectra of the fragments have two strong characteristic peaks at 794 and $842 \mathrm{~cm}^{-1}$ and one weak characteristic peak at $292 \mathrm{~cm}^{-1}$ (Fig. 3b, R8) indicative of ringwoodite. Additional peaks near $585 \mathrm{~cm}^{-1}$ and $660 \mathrm{~cm}^{-1}$ (Fig. 3b, R8) have been documented from ringwoodite and olivine, 

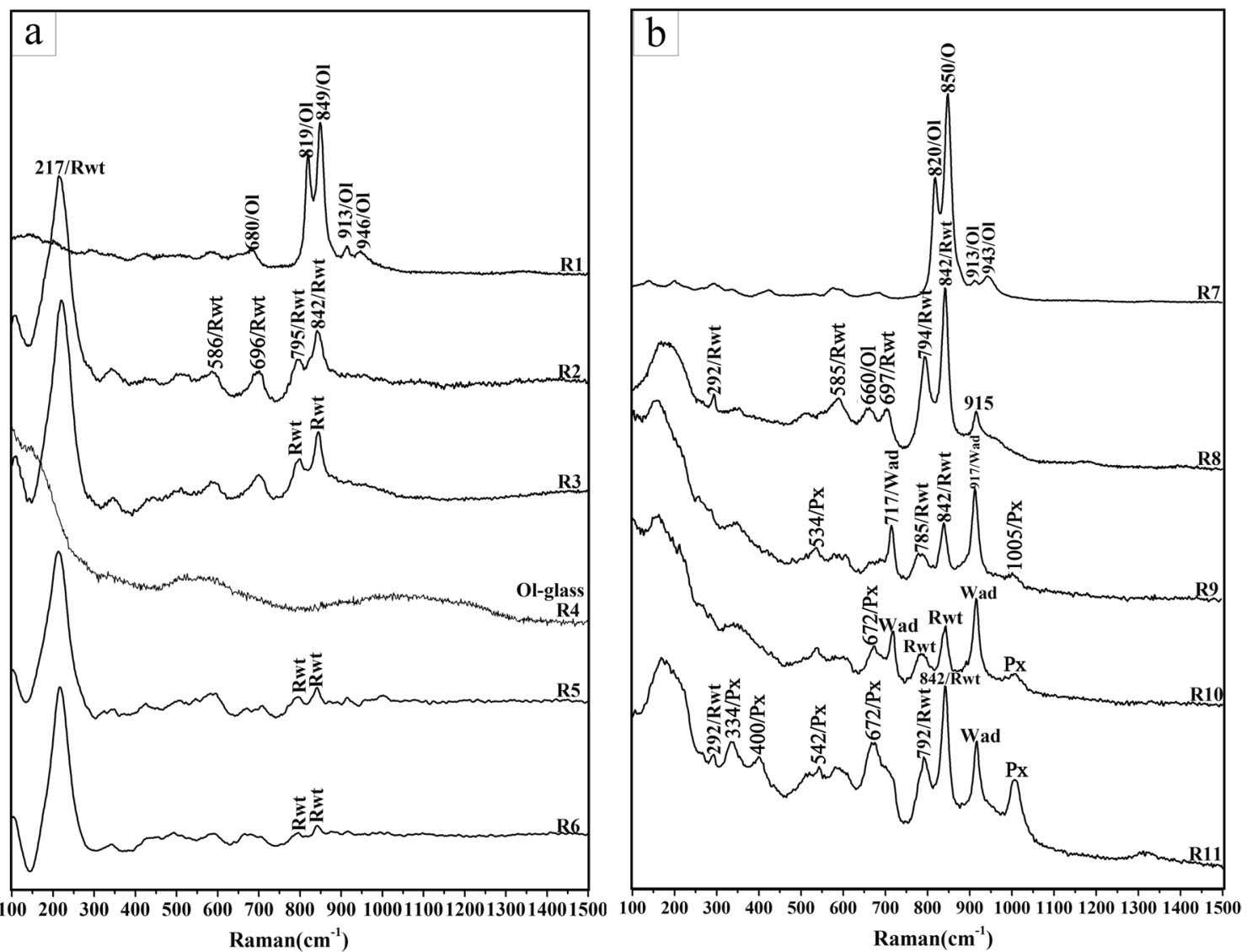

Fig. 3 Raman spectra of various polymorphs of olivine (OI). a Raman spectra of olivine (R1), lamellar ringwoodite (R2-R3), olivine glass (R4), polycrystalline, and ringwoodite microlite clusters (R5-R6). b Raman spectra of olivine (R7), polycrystalline ringwoodite aggregates (R8), rod-like ringwoodite, wadsleyite, and pyroxene (R9-R11). Wad wadsleyite, Px pyroxene; others are the same as above

respectively (Walton and McCarthy, 2017; Acosta-Maeda et al. 2013). The peak at $697 \mathrm{~cm}^{-1}$ may also be derived from the ringwoodite, similar to the peak at $692 \mathrm{~cm}^{-1}$ of the ringwoodite (Takenouchi et al. 2018). In addition, the pigeonite fragments (Fig. 4c) in the shock-induced melt vein have not been transformed to high-pressure polymorphs or glass based on Raman analysis (Figure S1, \#3, see Additional file 1 for details). The Mg\#-numbers of the ringwoodite are 64.1-62.4, comparable with the host olivine (Table S4, see Additional file 2 for details).

TEM observations of the polycrystalline ringwoodite aggregates (FIB-slice \#2, Fig. 5b) confirm that these assemblages are nano-sized ringwoodite with the size of 100 to $500 \mathrm{~nm}$ and $120^{\circ}$ conjunction. The TEM-EDS spot analysis (Additional file 2: Table S6) and element mapping images (Fig. $6 \mathrm{a}-\mathrm{C}$ ) show that the Mg\#-numbers of ringwoodite grains are relatively homogeneous $(\mathrm{Mg \#}$ 64.8-61.8), which are consistent with the EPMA analyses data (Mg\# 64.1-62.4, Additional file 2: Table S4). The TEM observations show that the nano-sized ringwoodite has various crystallographic orientations.

\section{Submicron-sized rod-like ringwoodite coexisting with the wadsleyite in shock-induced melt vein matrix}

The matrix of the shock-induced melt vein in touch with the polycrystalline ringwoodite fragments consists mainly of submicron-sized rod-like grains, with the presence of abundant sulfide spheres (Fig. $4 \mathrm{~b}-\mathrm{f}$ ). The presence of ringwoodite, wadsleyite, and pyroxene in the matrix was confirmed by Raman analyses (Fig. 3, R9-R11). The Raman spectra show strong characteristic peaks of ringwoodite at 785/792 and $842 \mathrm{~cm}^{-1}$; weak characteristic peaks of pyroxene at 334, 400, 534, 542, and $1005 \mathrm{~cm}^{-1}$; and weak peaks of wadsleyite at 917 and $717 \mathrm{~cm}^{-1}$. Electron probe analyses with a defocused beam of the ringwoodite-wadsleyite-pyroxene assemblages show slightly more enriched in $\mathrm{SiO}_{2}$ (41.7-44.5 wt\%), $\mathrm{Al}_{2} \mathrm{O}_{3}(1.57-3.74 \mathrm{wt} \%), \mathrm{Cr}_{2} \mathrm{O}_{3}(0.29-0.41 \mathrm{wt} \%)$, and $\mathrm{CaO}$ (2.02-3.31 wt\%) than the polycrystalline ringwoodite aggregates (Table S4, see Additional file 2 for details).

The TEM observations of the fine-grained melt matrix (FIB-slice \#2, Fig. 5c-f) depict in detail the microstructures and the corresponding chemical compositions of 

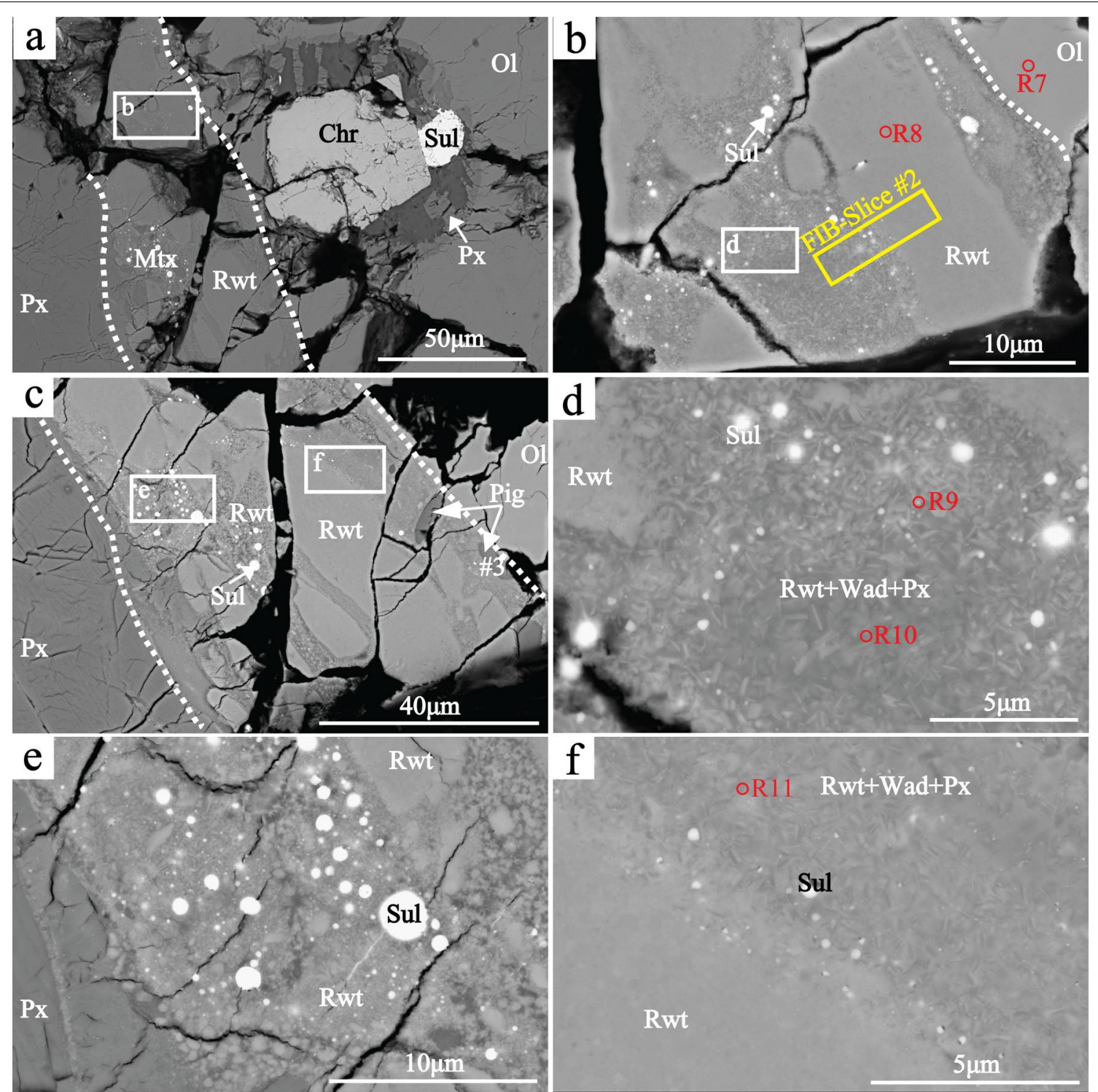

Fig. 4 BSE images of polycrystalline ringwoodite, rod-like ringwoodite and the coexisting wadsleyite in the shock-induced melt vein. a Low magnification BSE image shows a partially melted region (outlined with dotted line) with the presence of ringwoodite (Rwt) and matrix (Mtx). $\mathbf{b}$ Enlarged image of the white box " $b$ " in a shows the polycrystalline ringwoodite with olivine (Ol) fragment pseudomorph. The yellow box is the position of FIB-slice \#2. R7 and R8 are Raman analysis positions. $\mathbf{c}$ Higher magnification BSE image of the partially melted region in a, showing the presence of ringwoodite fragment and matrix. Pigeonite fragments (analyzed by Raman spectrum \#3) are indicated by the white arrow. $\mathbf{d}$ Enlarged image of white box "d" in $\mathbf{b}$. Raman spectra (R9 and R10) the intergrowth of ringwoodite, wadsleyite (Wad) and pyroxene (Px). The white spheres are sulfide (Sul). e Enlarged image of the white box "e" in c shows the texture of the shock-induced melt. The presence of ringwoodite was confirmed by Raman analysis, and the white spheres are sulfide. $\mathbf{f}$ Enlarged image of the white box "f" in c shows the intergrowth of rod-like ringwoodite, wadsleyite, and pyroxene in the matrix and the polycrystalline ringwoodite fragment. The small white grains are sulfide. Other abbreviations are the same as above

the ringwoodite, wadsleyite, and clinopyroxene. According to the BF-TEM images and SAED patterns, some rodlike ringwoodite (100-300 $\mathrm{nm}$ in size) (Fig. 5d, e) with the length-to-width ratio of $\sim 3$ and the wadsleyite (100$200 \mathrm{~nm}$ in width) (Fig. 5c, d) are distributed randomly. TEM-EDS analyses of the ringwoodite and wadsleyite crystals reveal highly heterogeneous compositions (Additional file 2: Table S6 and Fig. 6d-f) and the wadsleyite (Mg\# 77.5-67.2) is Fe-depleted than the coexisting ringwoodite (Mg\# 76.2-35.5). TEM-EDS elemental mapping images (Fig. 6f) and TEM-EDS spot analyses (Additional file 2: Table S6) show that the interstitial regions between 

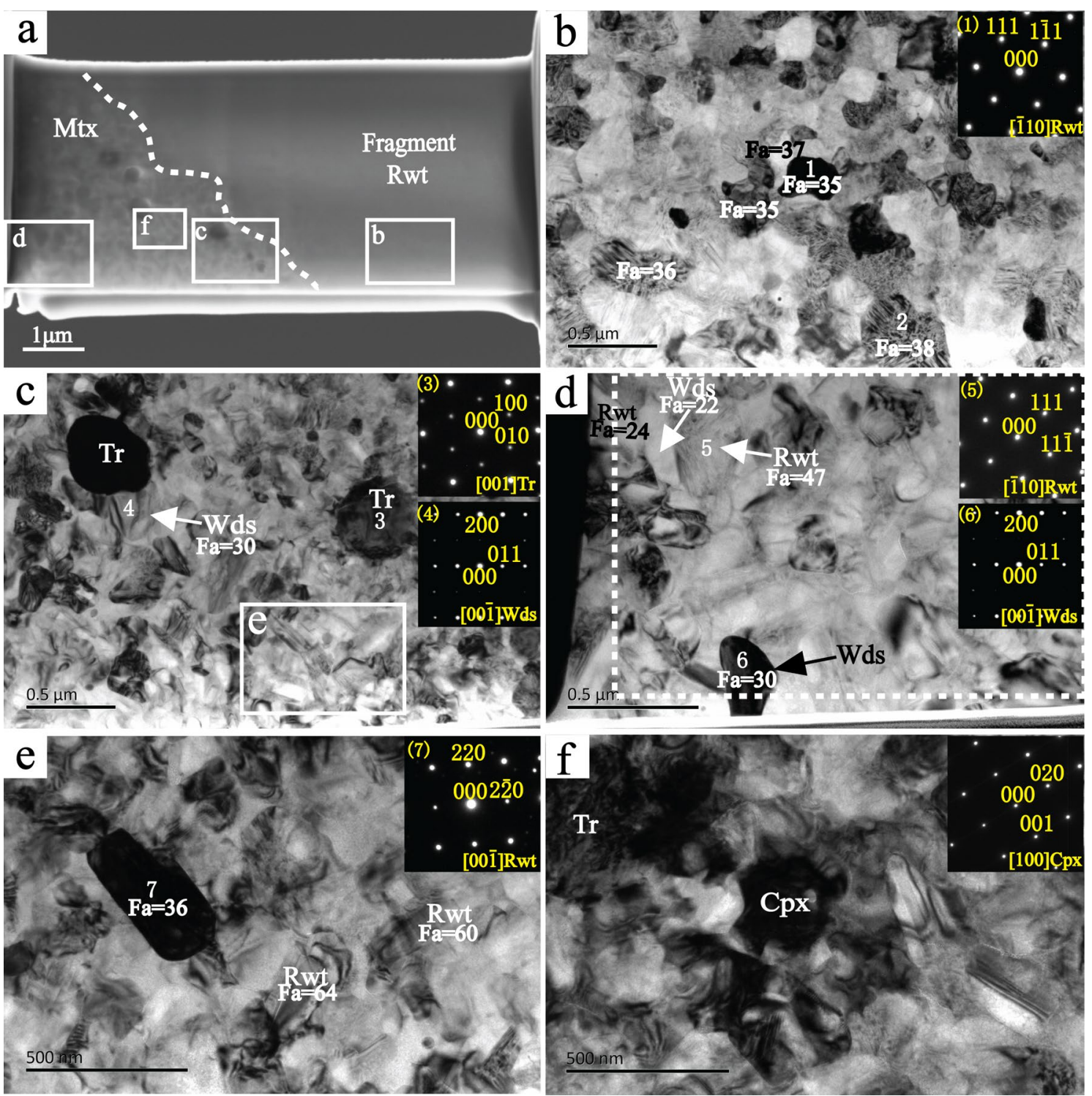

Fig. 5 BF-TEM images, SAED patterns of polycrystalline ringwoodite, rod-like ringwoodite and the coexisting wadsleyite. a SE image of FIB-slice \#2 consists of two parts. $\mathbf{b}$ Enlarged BF-TEM image of the white box "b" in $\mathbf{a}$. SAED pattern of grain 1 corresponds to ringwoodite. $\mathbf{c}$, $\mathbf{d}$ Enlarged BF-TEM images of the white box" $\mathrm{c}$ " and " $\mathrm{d}$ " from $\mathbf{a}$ in the matrix. SAED patterns of representative grains indicate that they are troilite, ringwoodite, and wadsleyite, respectively. The white dotted-line box represents the TEM-EDS elemental mapping region. e Enlarged BF-TEM images of the white box " $\mathrm{e}$ " in $\mathbf{c}$. The rod-like ringwoodite was identified from the SAED pattern. $\mathbf{f}$ clinopyroxene was identified by SAED pattern and TEM-EDS. Tr troilite, C $p x$ clinopyroxene, others are the same as above

the ringwoodite and wadsleyite contain $48.8-54.5 \mathrm{wt} \%$ $\mathrm{SiO}_{2}, 1.9-2.2$ wt\% $\mathrm{Al}_{2} \mathrm{O}_{3}, 3.8-6.9$ wt\% $\mathrm{CaO}, 19.2-22.4$ $\mathrm{wt} \% \mathrm{FeO}$, and 15.7-21.8 wt\% MgO. From the interstitial region, the existence of clinopyroxene $\left(\mathrm{Fs}_{34} \mathrm{En}_{51} \mathrm{Wo}_{15}\right)$ was confirmed based on the SAED patterns (Fig. 5f) and TEM-EDS analyses (Table S6, see Additional file 2 for details).

\section{Ringwoodite microlite clusters in the shock-induced melt vein}

The microlites of ringwoodite cluster together as small grain-like assemblages in the glassy matrix of a shockinduced melt vein $(20 \mu \mathrm{m}$ in width) cutting through the host olivine phenocryst (Fig. 7). Raman spectra of these microlites show the peaks of ringwoodite at 795 and $842 \mathrm{~cm}^{-1}$ (Fig. 3a, R6). It is also noticed that the grain sizes of the ringwoodite microlites are larger at the center of the shock-induced melt vein than those at the 


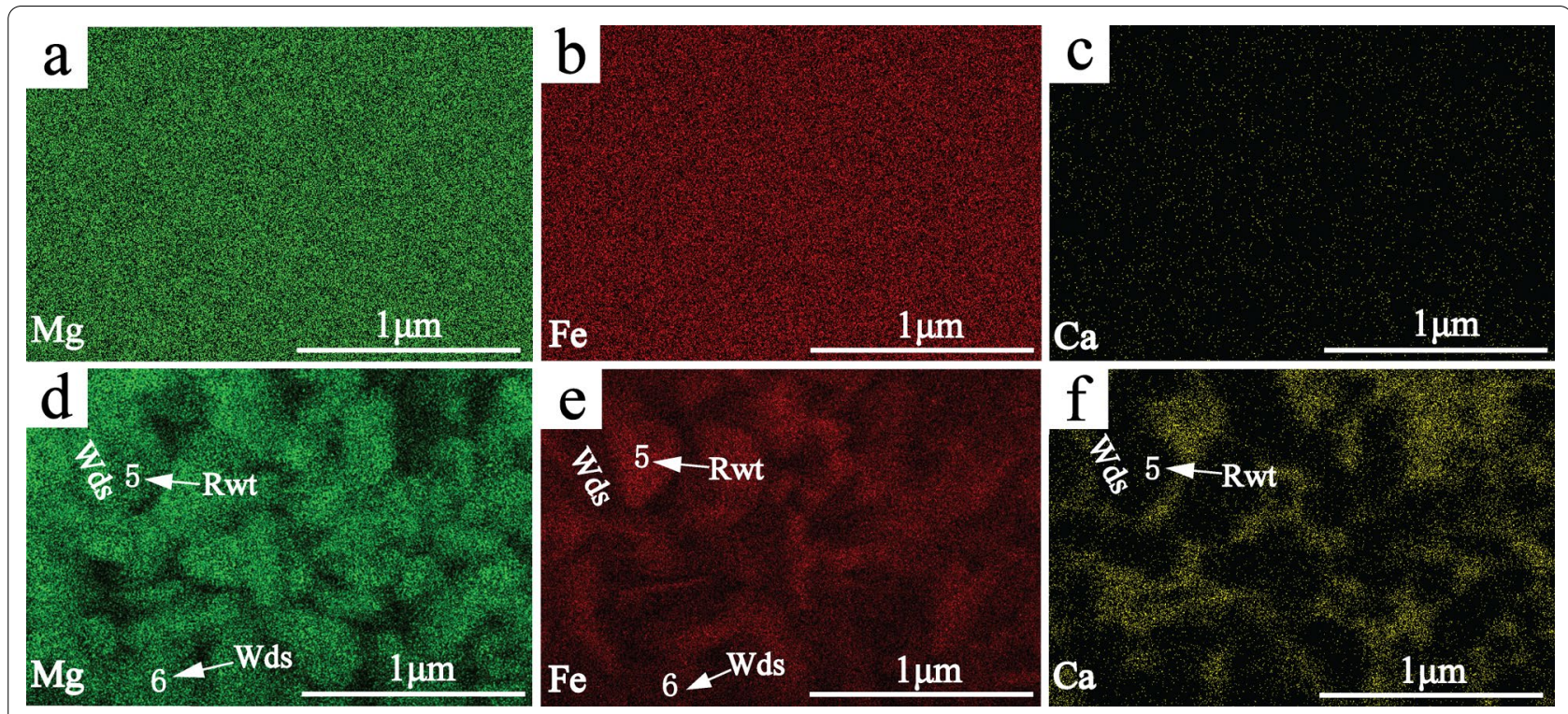

Fig. 6 TEM-EDS elemental mapping images of Mg, Fe, and Ca of polycrystalline ringwoodite and matrix (Mtx). a-c Elemental mapping images of $\mathrm{Fe}, \mathrm{Mg}$, and $\mathrm{Ca}$ for polycrystalline ringwoodite in Fig. $5 \mathrm{~b}$ show the homogeneous composition distribution. $\mathbf{d}$-f Elemental mapping images of $\mathrm{Fe}, \mathrm{Mg}$, and $\mathrm{Ca}$ in the matrix from white dotted-line box in Fig. $5 \mathrm{~d}$ shows that the distributions of Fe, $\mathrm{Mg}$, and $\mathrm{Ca}$ are heterogeneous. Between the ringwoodite and wadsleyite, there exists Ca-rich interstitial material
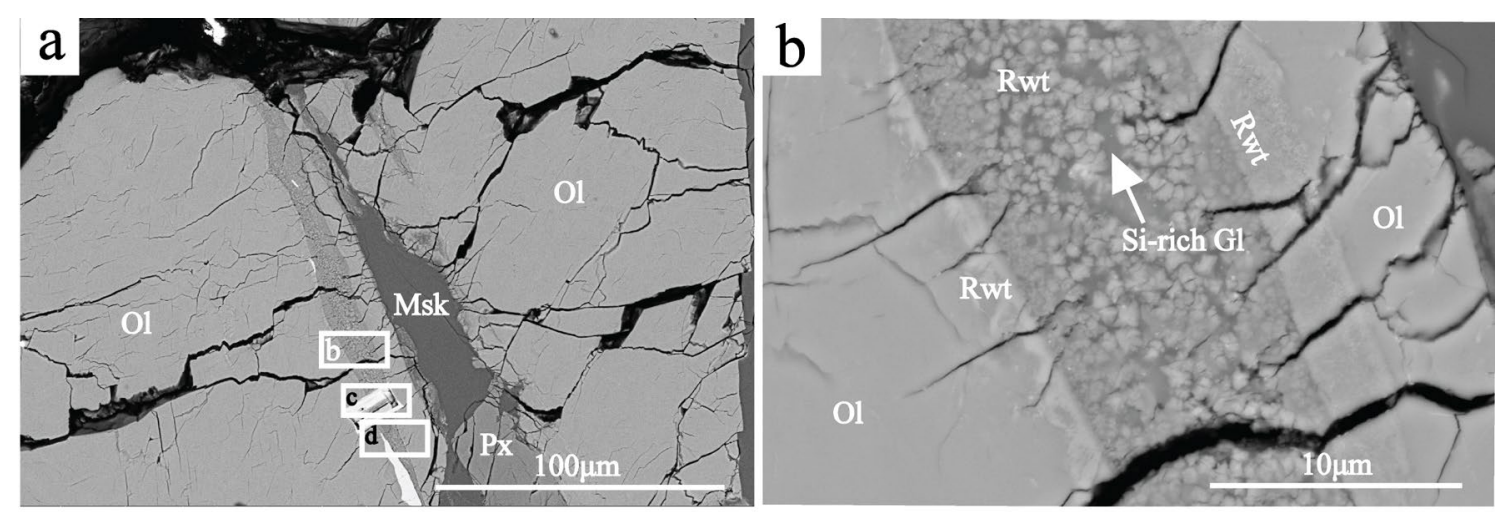

c
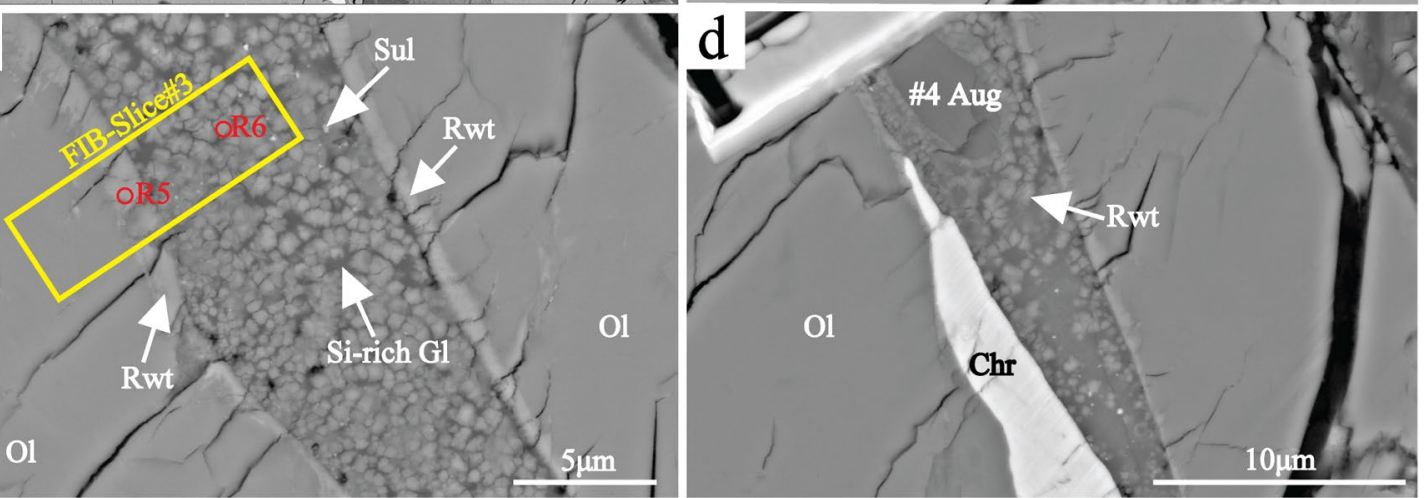

Fig. 7 BSE images of the granular ringwoodite. a A shock-induced melt vein ( $20 \mu \mathrm{m}$ in width), cutting through olivine. The regions marked by white boxes "b", "c", and "d" are shown in $\mathbf{b}, \mathbf{c}, \mathbf{d}$, respectively. b Submicron-sized ringwoodite grains embedded in a Si-rich glass (GI). Note larger ringwoodite grains in the center than those adjacent to the rims. The olivine walls in contact with the vein have been transformed into ringwoodite too. c Similar texture of $\mathbf{b}$. The yellow box shows the position of FIB-slice \#3. Two Raman analyses are marked as R5 and R6. d Ringwoodite microlite clusters and an augite in the melt vein. Raman spectrum \#4 confirms the augite. Chr chromite; others are the same as above 
rims (Fig. 7b). A few tiny grains of sulfide (Fig. 7c) and one augite grain $\left(\mathrm{Fs}_{17.1-19.3} \mathrm{En}_{48.1-50.3} \mathrm{Wo}_{30.4-34.8}\right.$ analyzed by EDS) (Fig. 7d, Figure S1, \#4, see Additional file 1 for details) were also found in the shock-induced melt vein. Because of the small size of ringwoodite in the shockinduced melt vein, EPMA analyses on these submicron ringwoodite crystals have unavoidably overlapped nearby glass. The bulk composition of the shock-induced melt vein was determined with a defocused beam of EPMA, with 44.6-46.7 wt\% $\mathrm{SiO}_{2}, 2.30-2.86$ wt $\% \mathrm{Al}_{2} \mathrm{O}_{3}, 3.20-$ $3.66 \mathrm{wt} \% \mathrm{CaO}$, and $0.29-0.34 \mathrm{wt} \% \mathrm{Na}_{2} \mathrm{O}$ (Table S4, see Additional file 2 for details).

The SE image (Fig. 8a) of the whole FIB-slice \#3 (marked in Fig. 7c) shows the olivine, the ringwoodite adjacent to the melt vein, and the shock-induced melt vein (ringwoodite microlite clusters and glass) from left to right. The BF-TEM images depict the ringwoodite microlites (100-500 $\mathrm{nm}$ in size) clumping together embedded in glassy matrix. A few small sulfide spheres can be noticed in the glassy matrix too (Fig. 8c and f). The weak streaks around the diffraction spot in the SAED pattern (Fig. 8d) of the ringwoodite indicate the presence of stacking faults on (110). The TEM-EDS results reveal heterogeneous compositions of the ringwoodite microlites, with the Mg\#-numbers ranging from 72 to 58 (Table S7, see Additional file 2 for details). In addition, the TEM-EDS spot analyses show that the glassy matrix interstitial to the ringwoodite microlites is rich in $\mathrm{SiO}_{2}$ (52.3-69.7 wt\%), $\mathrm{Al}_{2} \mathrm{O}_{3}$ (2.04.6 wt\%), and $\mathrm{CaO}$ (0.3-6.9 wt\%) (Table S7, see Additional file 2 for details).

Additionally, it is noted that the point of contact between the olivine and the shock-induced melt vein appears brighter than the interior of the host olivine in BSE image (Figs. 7b and c). Laser Raman spectra confirm that the contact interface which we refer to below as 'walls' is ringwoodite (Fig. 3a, R5). Based on the observations of TEM, the lamellar ringwoodite walls at the contact between the olivine and melt vein consist of polycrystalline ringwoodite grains (Figure S2b, see Additional file 1 for details). EPMA analyses of the lamellar ringwoodite (Mg\# 64.9) show identical chemical compositions (Table S4, see Additional file 2 for details) to the host olivine (Mg\# 64.6). Away from the melt vein, the ringwoodite platelets have a crystallographic relationship of $\{111\}_{\text {Rwt }} / /(100)_{\mathrm{Ol}}$ with the host olivine (Figure S2c, see Additional file 1 for details).
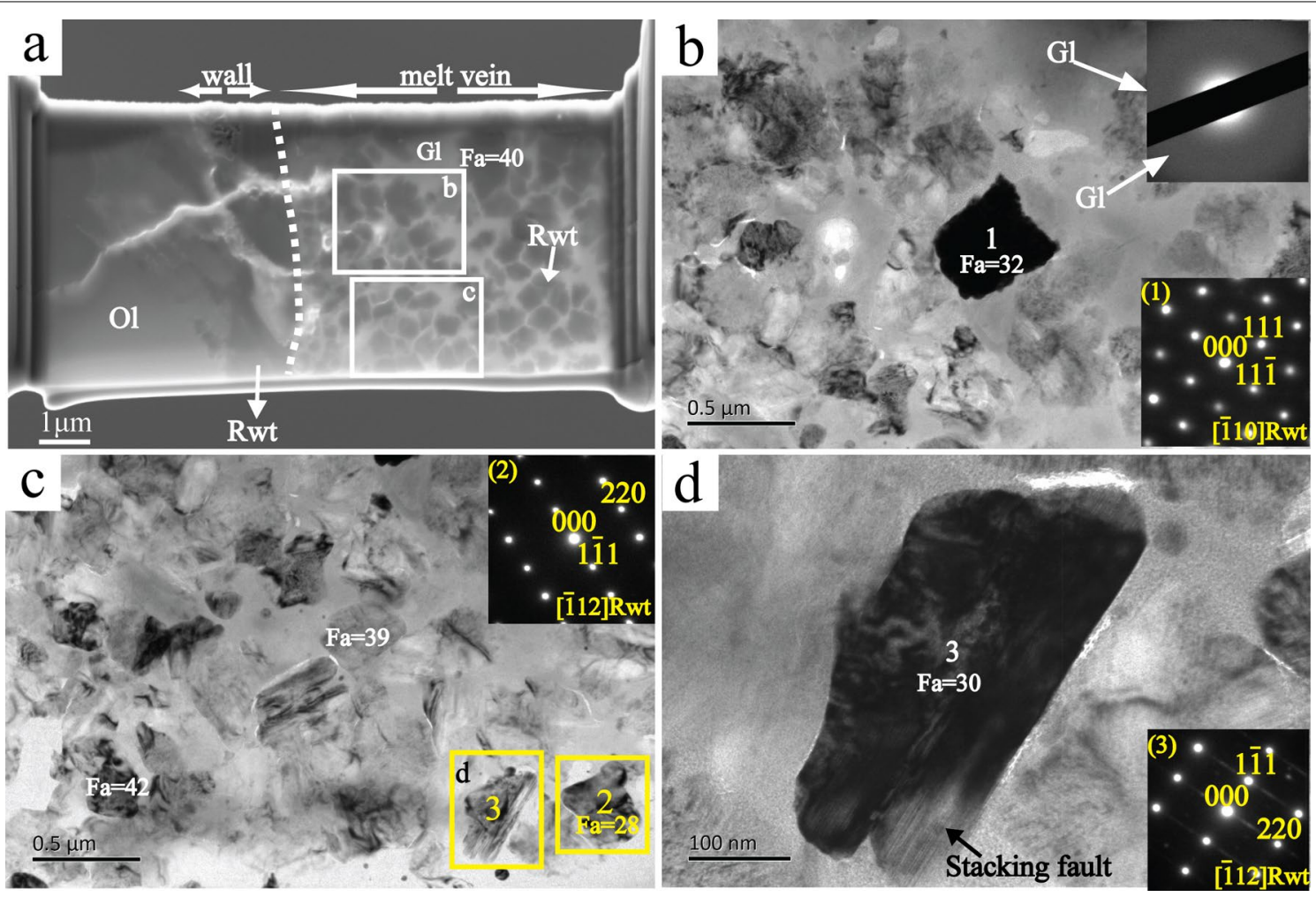

Fig. 8 BF-TEM images of FIB-slice \#3 of the ringwoodite microlite clusters. a SE image of FIB-TEM-slice \#3. b, c Enlarged BF-TEM images of the yellow rectangle "b" and "c" in $\mathbf{a}$. BF-TEM image and SAED pattern indicate that the ringwoodite grains are distributed in glass matrix. d Enlarged BF-TEM image of the yellow rectangle " $d$ " in c. SAED pattern of grain 3 shows that the ringwoodite has one set of weak stacking fault on (110) 
TEM-EDS spot analyses indicate that the ringwoodite platelets (Mg\# 58.8) are a little more iron-rich than the coexisting olivine (Mg\# 68.4) (Table S7, see Additional file 2 for details).

\section{Discussion}

Formation mechanisms of ringwoodite in NWA 8705 Solid-state transformation of ringwoodite lamellae

The olivine grains retained in or adjacent to the shockinduced melt pocket were partially transformed into ringwoodite lamellae (Fig. 2). The low-frequency Raman spectral peak of the ringwoodite lamellae at 212 $217 \mathrm{~cm}^{-1}$ (Fig. 3) is unusually strong, similar to that of ahrensite $(\mathrm{Fa}>50)$ in Dhofar 1970 and Tissint (Ma et al. 2016; Walton and McCarthy 2017). Nevertheless, the Fa-content of the ringwoodite lamellae in NWA 8705 is $\sim 36 \mathrm{~mol} \%$, much lower than that of ahrensite. Therefore, this low-frequency spectral peak may not be directly related to the high Fa-content, but could be attributed to the $\mathrm{Fe}-\mathrm{Mg}$ rearrangement at the (M1, M2) positions (Kleppe et al. 2002; Walton and McCarthy 2017). Ringwoodite lamellae adjacent to the shock-induced melt in NWA 8705 (Figs. 2c-d) seem to be composed of small crystals rather than being single ones and are orientated along specific orientations, which is similar to the lamellae in texture and morphology reported in other Martian meteorites (Greshake et al. 2013; Walton 2013). These ringwoodite lamellae were proposed to form via heterogeneous incoherent nucleation process as proposed in other meteorites (Greshake et al. 2013; Walton 2013). In addition, the $\mathrm{Mg \# -numbers} \mathrm{of} \mathrm{the} \mathrm{ringwoodite} \mathrm{lamellae}$ (Mg\# 64.2-62.7) here are relatively constant and similar to that of the host olivine (Mg\# 65.4-64; Table S3, see Additional file 2 for details), suggestive of no fractionation between both phases and an interface-controlled growth process (Sharp and De Carli 2006). Meanwhile, the single set of oriented lamellae was found in the interior of olivine (Fig. 2c), which is similar to those observed in Yamato 791,384 and Tissint (Miyahara et al. 2010, 2016; Walton et al. 2014). TEM observations (Fig. 2e, f) suggest that this single set of ringwoodite lamellae are thin in width (10-100 nm) and depict coherent crystallographic orientation with the host olivine $\{111\}_{\text {Rwt }} / /(100)_{\mathrm{Ol}}$ (Miyahara et al. 2010). It is known that coherent phase transformation occurs in two stages (1) a stacking fault develops in an original olivine grain by lattice plane slipping on $(100)_{\mathrm{Ol}}$; (2) coherent nucleation and growth of ringwoodite platelets occur on the stacking faults (Kerschhofer et al. 1996, 1998). The ringwoodite lamellae in NWA 8705 have a specific crystallographic relationship with the host olivine $\{111\}_{\mathrm{Rwt}} / /(100)_{\mathrm{Ol}}$ (Fig. 2e, f), which is the evidence for a coherent phase transformation mechanism (Tomioka and Miyahara 2017; Miyahara et al.
2010). In addition, the Mg\#-numbers of the ringwoodite lamellae (Mg\# 63-60) are relatively constant and similar to that of the host olivine (Mg\# 62.4-60.9) (Tables S5, see Additional file 2 for details), suggestive of no compositional fractionation between them and consistent with an interface-controlled growth mechanism (Sharp and De Carli 2006; Kerschhofer et al. 1996).

The thin ringwoodite lamellae adjacent to the melt vein also have a crystallographic relationship of $\{111\}_{\text {Rwt }} / /$ $(100)_{\mathrm{Ol}}$ with the host olivine (Figure S2c, see Additional file 1 for details), suggestive of a coherent nucleation process (Miyahara et al. 2010; Walton et al. 2014). However, differences in chemical compositions between the host olivine (Mg\# 69.9-66.3) and the ringwoodite (Mg\# 63.254.4) were detected (Tables S7, see Additional file 2 for details), implying a Fe-Mg exchanging with Fe preferentially partitioned to ringwoodite. Thus, the growth of the ringwoodite lamellae was $\mathrm{Fe}-\mathrm{Mg}$ diffusion-controlled as proposed by Sharp and De Carli (2006).

\section{Solid-state transformation of polycrystalline ringwoodite aggregates}

The polycrystalline ringwoodite aggregates (Fig. 4b, c) were transformed from the pre-existing olivine fragments with rounded outlines. The TEM observations (Fig. 5b) of the polycrystalline ringwoodite $(100-500 \mathrm{~nm}$ ) reveal random crystallographic orientation of the crystals with triple junctions. The random orientations and homogeneous distributions of the polycrystalline ringwoodite, similar to that of some shocked meteorites (Xie and Sharp 2007; Chen et al. 1996; Putnis and Price 1979; Wang et al. 2017), may indicate a solid-state homogeneous nucleation throughout the olivine fragment (Sharp and De Carli 2006; Xie and Sharp 2007). STEM-EDS mapping images (Fig. 6a-c), TEM-EDS (Table S6, see Additional file 2 for details), and EPMA spot analyses (Table S4, see Additional file 2 for details) show that the Mg\#-numbers of the polycrystalline ringwoodite (Mg\# 65-62) are relatively constant and close to that of the adjacent olivine (Mg\# 66-64), implying that there was no $\mathrm{Fe}-\mathrm{Mg}$ interdiffusion during transformation. It is possible that the polycrystalline ringwoodite was produced via the interface-controlled growth process as proposed by previous studies (Kerschhofer et al. 1998; Mosenfelder et al. 2001; Miyahara et al. 2010; Sharp and De Carli 2006).

In addition, the lamellar ringwoodite walls in contact with the very thin shock-induced melt vein (Fig. 7c, d) are composed of polycrystalline ringwoodite with random crystallographic orientations (Additional file 1: Figure S2) and there is no specific crystallographic orientation between original olivine and ringwoodite, indicating of an incoherent nucleation (Tomioka and Miyahara 
2017). Mg\#-numbers (Mg\# 68-64) of ringwoodite here are comparable with the host olivine (Mg\# 69.9-66.3) (Additional file 2: Table S7), manifesting an interfacecontrolled growth mechanism (Sharp and De Carli 2006; Xie and Sharp 2007) as discussed above.

\section{Melt crystallization of submicron-sized rod-like ringwoodite coexisting with the wadsleyite}

The fine-grained matrix of the shock-induced melt vein consists mainly of ringwoodite, wadsleyite, clinopyroxene, and a few metal-sulfide spheres (Fig. 4). As in other shocked meteorites (Hu and Sharp 2016; Xie et al. 2006a; Martinez et al. 2019), this mixture in the shock-induced melt vein is inferred to represent immiscible silicate and metal-sulfide liquids that were rapidly quenched although the mineral assemblages are different. Additionally, the bulk compositions of the matrix (Table S8, see Additional file 2 for details) are relatively rich in $\mathrm{SiO}_{2}$, $\mathrm{Al}_{2} \mathrm{O}_{3}$, and $\mathrm{CaO}$ compared with the olivine fragments, indicating that the shock-induced melt vein matrix was mainly mixed with olivine, some pyroxene, and probably plagioclase. The TEM observations indicate that ringwoodite and wadsleyite grains have random crystallographic orientations and they are distributed randomly (Fig. 5c, d). The results of elemental mapping images and STEM-EDS spot analyses show that the fine-grained matrix is heterogeneous (Fig. 6d-f) and there exist large compositional ranges between the coexisting ringwoodite (Mg\# 76.2-35.5) and wadsleyite (Mg\# 77.5-67.2) (Additional file 2: Table S6) with the ringwoodite more FeO-enriched than the coexisting wadsleyite. Two different Raman spectrum peaks of ringwoodite at 785 and $792 \mathrm{~cm}^{-1}$ also indicate the large compositional ranges of ringwoodite (Feng et al. 2011), although the corresponding $\mathrm{Fa}$-contents of ringwoodite $\left(\mathrm{Fa}_{24.8-64.5}\right)$ are slightly lower than the reports $\left(\mathrm{Fa}_{72}\right.$ and $\left.\mathrm{Fa}_{48}\right)$ of Feng et al. (2011). The inconsistency in the Fa-contents here compared with that of the reports (Feng et al. 2011) may be related to the uncertainty or influence by the underlying material of TEM-EDS point analyses. The observed difference in composition between the sub-micron rod-like ringwoodite and the coexisting wadsleyite is consistent with Fe-Mg partition between them during the crystallization from the shock-induced melt (Miyahara et al. 2008, 2009), indicative of the fractional crystallization of ringwoodite and wadsleyite from the shock-induced melt.

\section{Melt crystallization of the ringwoodite microlite clusters}

The ringwoodite microlite clusters in the glass matrix of the very thin melt vein (Fig. 7) show a large range of composition (Mg\# 72-58) and different crystallographic orientations (Fig. 8). The glass matrix is rich in $\mathrm{SiO}_{2}$, $\mathrm{CaO}$, and $\mathrm{Al}_{2} \mathrm{O}_{3}$ compared to the coexisting ringwoodite (Table S7, see Additional file 2 for details), indicating that the shock-induced melt vein was not mono-olivine melt, but mixed with some plagioclase and probably pyroxene too. This is confirmed by the bulk composition of the shock-induced melt vein (Table S8, see Additional file 2 for details). The heterogeneous compositions of the ringwoodite and the presence of the glass matrix convincingly suggest that the ringwoodite crystallized from melt, different from the common coexistence of ringwoodite with wadsleyite, clinopyroxene and other phases in typical shock-induced melt veins depicted above and in other meteorites (Xie et al. 2006a, 2011; Fritz and Greshake 2009; $\mathrm{Hu}$ and Sharp 2016). It is also observed that the ringwoodite grains become smaller from the center of the vein towards the rim (Fig. 7b). This is a typical feature of crystallization of shock-induced melt veins because of a faster cooling rate at the rim, further confirming the crystallization of ringwoodite. In addition, some ringwoodite grains developed a set of stacking fault observed with TEM (Fig. 8d), which is probably due to the stress induced by the deformation of the crystals during segmentation or growth defects (Miyahara et al. 2008; Pittarello et al. 2015).

\section{Post-shock P-T conditions constrained by ringwoodite in NWA 8705}

As discussed above, the lamellar and polycrystalline ringwoodite were produced by the solid-state transformation of olivine. The transformation depends on the P-T condition and the chemical composition of olivine. According to the $\mathrm{P}-\mathrm{T}$ phase diagram of olivine with $\mathrm{Fa}_{35}$ (Fig. 9)

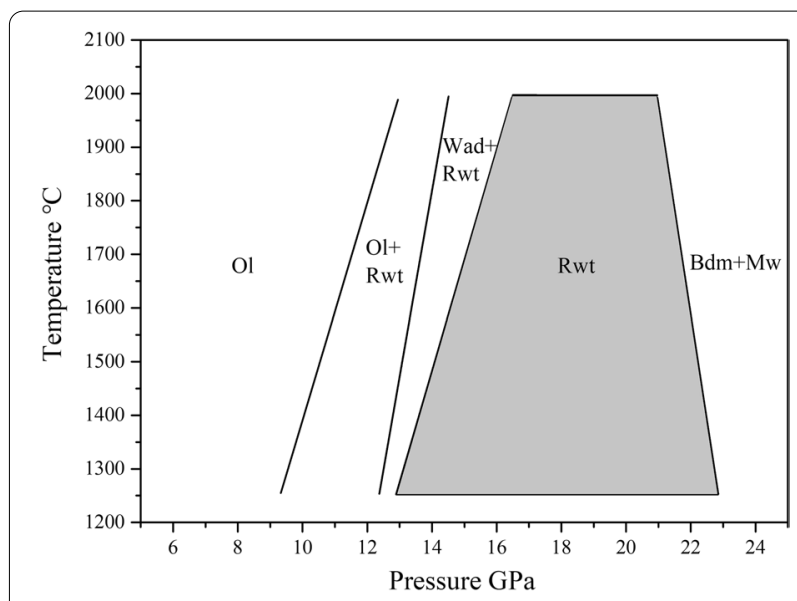

Fig. 9 Pressure-temperature phase diagram for olivine $\left(\mathrm{Fo}_{65}\right)$ after Ito and Takahashi (1989), Frost (2008), Tomioka and Miyahara (2017). The shaded region corresponds to the ringwoodite stability field. Bdm, bridgmanite; Mw, magnesiowüstite; others are the same as above 
modified from the pressure-temperature-composition phase diagram of olivine (Tomioka and Miyahara 2017; Frost 2008; Ito and Takahashi 1989; Katsura and Ito 1989), olivine and ringwoodite have coexisted in the olivine grain in contact with a shock-melt vein, indicating that the shock pressure is $9-13 \mathrm{GPa}$ or more. However, the pressure condition could be underestimated because the initiation of the solid-state transformation of olivine involves a breakage of the $\mathrm{Si}-\mathrm{O}$ bond, which requires to some extent a higher pressure than the value indicated by the phase boundary, and the process is kinetically sluggish (Sharp and De Carli 2006).

Some ringwoodite or wadsleyite crystallized from shock-induced melts. Crystallization processes at high temperatures only need to overcome lower kinetic barriers, requiring no pressure overstepping (Sharp and De Carli 2006). Consequently, in order to constrain the P-T condition more accurately, we adopt another phase diagram (Fig. 10) built from high-pressure melting experiments on the Allende carbonaceous chondrites (Agee et al. 1995; Asahara et al. 2004) which has a bulk FeO abundance (27 wt\%) closer to the shock-induced melts in NWA 8705 (19-24 wt\%) than the peridotite KBL-1 (9 wt\%) (Zhang and Herzberg 1994; Trønnes and Frost 2002).

The shock-induced melt vein (Fig. 4) contains ringwoodite, wadsleyite, and clinopyroxene, but we could not identify the majorite reported in other meteorites (e.g., Xie et al. 2006a, 2011; Tomioka and Miyahara 2017; and references therein). The mineral assemblages with the absence of majorite in the shock-induced melt vein (Fig. 4) in NWA 8705 is consistent with the metastable crystallization of subsolidus phases from

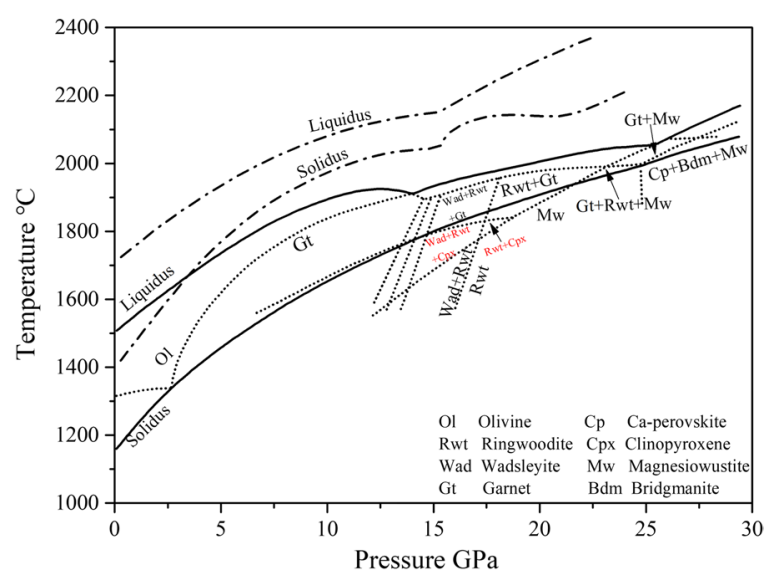

Fig. 10 A simplified P-T diagram for the Allende meteorite (solid lines) after Agee et al. (1995) and Asahara et al. (2004), and the P-T diagram for the peridotite (dot-dash lines) from Zhang and Herzberg (1994) and Trønnes and Frost (2002) a supercooled liquid where nucleation of the majorite was inhibited ( $\mathrm{Hu}$ and Sharp 2016; Xie et al. 2006b). The sulfide spheres throughout the matrix are also the evidence for a fast quench. Based on the Allende phase diagram (Fig. 10), ringwoodite, wadsleyite, and clinopyroxene $\left(\mathrm{En}_{51} \mathrm{Fs}_{34} \mathrm{Wo}_{15}\right)$ could crystallize at a condition of 14-17 GPa, 1650-1750 ${ }^{\circ} \mathrm{C}$. In addition, the pigeonite $\left(\mathrm{En}_{67.5} \mathrm{Fs}_{24.5} \mathrm{Wo}_{8}\right)$ relict fragments in the shock-induced melt constrain the pressure conditions of the shockinduced melt vein to below the pyroxene-majorite phase boundary that is $<16 \mathrm{GPa}$ at $1800{ }^{\circ} \mathrm{C}$ (Tomioka and Miyahara 2017; Ozawa et al. 2010; Ohtani et al. 1991). Therefore, we estimate the crystallization pressure and temperature of the shock-induced melt vein to be 14-16 GPa, $1650-1750{ }^{\circ} \mathrm{C}$, respectively. This $\mathrm{P}-\mathrm{T}$ condition is similar to that of LL6 chondrite NWA 757 and L6 Château-Renard (Baziotis et al. 2018; Hu and Sharp 2016). Ca-rich pyroxene (augite) in another shock-induced melt vein (Fig. 7d) can be stable up to $18 \mathrm{GPa}$ (Oguri et al. 1997). The overlap in stability fields between ringwoodite (Fig. 9) and Ca-rich pyroxene constrains the crystallization pressure of the shock vein to be 13-18 GPa. This pressure estimate agrees with the overlap in the pressure stability field of those minerals (ringwoodite + clinopyroxene, 16-18 GPa) at the phase diagram for Allende (Fig. 10). Within this pressure range, the inferred crystallization temperature is $1750-1850{ }^{\circ} \mathrm{C}$. Thus, we estimate that the crystallization pressure and temperature of the shock-induced melt vein is $16-18 \mathrm{GPa}, 1750-1850{ }^{\circ} \mathrm{C}$, respectively.

Very thin shock-induced melt vein and melt vein margins are most rapidly quenched and most likely to contain crystallization products recording the shock pressure condition (Sharp and De Carli 2006; Hu and Sharp 2016). The two melt veins discussed above are thin $(\leq 60 \mu \mathrm{m})$ and lower pressure mineral assemblages were not observed in the core from the two thin shock-induced melt veins, suggesting that the crystallization occurred during shock pressure (Xie et al. 2006b). The two shockinduced melt veins discussed above are similar in chemical bulk compositions (Table S8, see Additional file 2 for details). The differences in mineralogy and micro-texture seem to be related to crystallization pressure and cooling rate (see quench time in the following section). The cooling rate of the melt vein $(\sim 60 \mu \mathrm{m})$ was not rapid enough to quench to the glass compared with the thinner shock-induced melt vein which recorded the possible shock pressure. The shock-induced melt vein $(\sim 60 \mu \mathrm{m})$ may crystallize quickly during a slight decrease in pressure and did not produce core-edge zoning of minerals (Sharp and De Carli 2006). Therefore, the very thin shock-induced melt vein $(20 \mu \mathrm{m})$ should record the shock 
pressure $18 \mathrm{GPa}$ based on the crystallization pressure condition discussed above.

\section{Constraints on quench time and shock pressure duration in NWA 8705}

The mineral assemblages crystallizing in shock-induced melt veins depend on the quench time and the duration of the shock pressure (Sharp and De Carli 2006; Xie et al. 2006a). If the quench time is much longer than the shock pressure duration, crystallization will occur during a pressure release and we should see a difference in mineralogy between the vein edge and the vein center. If the quench time is shorter or a little longer than the shock pressure duration, crystallization occurred at constant pressure or during a slight release of pressure and we should see mineral assemblages of similar pressure stabilities throughout a given melt vein (Walton et al. 2014; Walton 2013; Sharp and De Carli 2006; Xie et al. 2006b). The quench time $(t)$ of a shock-induced melt vein can be simply calculated by a thermal conduction equation, $t=L^{2} / \alpha$, where $\mathrm{L}=$ width of the shock-induced melt vein in meters, $\alpha$ is the thermal diffusion coefficient that is set to $10^{-6} \mathrm{~m}^{2} \mathrm{~s}^{-1}$ (Greshake et al. 2013; Fritz and Greshake 2009; Fritz et al. 2017). Thus, the quench times of the shock-induced melt veins $(20-60 \mu \mathrm{m}$ in width) in NWA 8705 are $0.4-3.6 \mathrm{~ms}$. The duration of the shock pressure can be constrained by using the transformation kinetic data for a given sample (Ohtani et al. 2004; Mosenfelder et al. 2001; Xie and Sharp 2007; Kerschhofer et al. 2000; Miyahara et al. 2010). Using calculated growth rates (Mosenfelder et al. 2001) and the size of ringwoodite, we can estimate the time required for ringwoodite growth in NWA 8705 as a function of temperature and thereby constrain the minimum duration of the shock pressure as Xie and Sharp (2007) has reported. At $18 \mathrm{GPa}$, if we expect the host olivine grains within and in contact with shock-induced melt veins to reach the temperature of $1700-1800 \mathrm{~K}$, the time required to grow a $500-\mathrm{nm}$ ringwoodite crystal in NWA 8705 is about $10-3.4$ ms. This minimum shock pressure duration $(10-3.4 \mathrm{~ms})$ is consistent with a shorter impact duration $(<100 \mathrm{~ms})$ of Martian meteorites compared to that of chondrites $(\sim 1 \mathrm{~s})$ (e.g., Beck et al. 2005; Fritz and Greshake 2009; Walton 2013; Walton et al. 2014).

\section{Implications for the findings of ringwoodite in NWA 8705}

As discussed above, there are four occurrences of ringwoodite found within an mm-scaled region in NWA 8705. Two conditions must be met for the formation and preservation of ringwoodite in the shocked meteorites. (1) The shock-induced formation of ringwoodite requires high enough temperature and pressure (Xie and Sharp 2007; Baziotis et al. 2013; Sharp and De Carli 2006) to provide the rapid transformation kinetics. (2) After the formation of ringwoodite, rapid cooling to low temperature $\left(<900{ }^{\circ} \mathrm{C}\right)$ is needed to preserve the phase during shock compression and subsequent decompression within the ringwoodite stability field (Greshake et al. 2013; Ming et al. 1991; Suzuki et al. 1980).

The findings of four occurrences of ringwoodite in NWA 8705 do satisfy the two conditions described above after our study. On the one hand, the four occurrences of ringwoodite are restricted to shock-induced melt veins and pockets where temperatures were high enough. The preservation of four occurrences of ringwoodite within the very small region in NWA 8705 could be largely attributed to the very thin width of the melt veins $(\sim 20-60 \mu \mathrm{m})$ or small shock-induced melt pockets (Sharp and De Carli 2006) which have very fast cooling rates and short quench times as discussed above.

More occurrences of ringwoodite in NWA 8705 may also be related to the higher $\mathrm{FeO}$-contents of olivine $\left(\mathrm{Fa}_{29-39}\right)$. Compared with the olivine in H-type $\left(\mathrm{Fa}_{16-20}\right)$, L-type $\left(\mathrm{Fa}_{23-26}\right)$, and LL-type $\left(\mathrm{Fa}_{27-32}\right)$ ordinary chondrites (Weisberg et al. 2006), most olivine grains in Martian meteorites are more fayalitic in composition, e.g., olivine-phyric shergottites, $\mathrm{Fa}_{23}-\mathrm{Fa}_{48}$; poikilitic shergottites, $\mathrm{Fa}_{16}-\mathrm{Fa}_{40}$; nakhlites, $\mathrm{Fa}_{56}-\mathrm{Fa}_{85}$; chassignites, $\mathrm{Fa}_{21}-\mathrm{Fa}_{46}$ (McSween 1985; Treiman 2005; Hewins et al. 2020; Sarbadhikari et al. 2016). The high FeO-contents olivine in the Martian meteorites can be transformed to ringwoodite or ahrensite under lower pressure in comparison with those in ordinary chondrites, based on the $\mathrm{Mg}_{2} \mathrm{SiO}_{4}-\mathrm{Fe}_{2} \mathrm{SiO}_{4}$ phase diagram (Presnall, 1995). Besides, ringwoodite with higher Fa-content could be preserved under relatively lower pressure. Therefore, ringwoodite with higher Fa-content is more likely to form and preserve in NWA 8705, broadening the pressure stability field of ringwoodite.

Four occurrences of ringwoodite in NWA 8705 are within and around shock-induced melt veins and pockets where pressure conditions may be almost homogeneous because shock-induced melt is a perfect pressure transmitting medium (Miyahara et al. 2016). The different formation mechanisms and arrangements are most likely due to temperatures difference at different locations within or close to the shock-induced melt veins and pockets (Miyahara et al. 2016; Hu and Sharp 2016, 2017). For instance, solid-state transformations of olivine usually occur at the olivine clasts within and adjacent to shock-induced melt veins and pockets in NWA 8705 and other meteorites (Miyahara et al. 2010; Ozawa et al. 2010; Xie and Sharp 2004) where the temperatures may have been high enough to overcome the nucleation energy barrier for incoherent and coherent nucleation 
of ringwoodite, so they can nucleate simultaneously (Wang et al. 2017). Nevertheless, the kinetics data indicate that the grain growth rate subsequent to nucleation in the incoherent process is much higher than that in the coherent process (Miyahara et al. 2016; Kerschhofer et al. 2000). Thus, incoherent grains may grow immediately to overtake coherent grain growth, and polycrystalline ringwoodites dominate adjacent to the shock-induced melt vein (Fig. 7), similar to that in Tissint and Yamato 791384 (Miyahara et al. 2016, 2010). With the increases of the distance from shock-induced melt vein and pocket, the ringwoodite changes from polycrystals to platelets (This study; Gillet and El Goresy 2013; Miyahara et al. 2016), which is likely because the temperatures are not sufficiently high to overcome the energy barrier for incoherent nucleation of polycrystalline ringwoodite, but are high enough for coherent nucleation of ringwoodite platelets (Wang et al. 2017; Kerschhofer et al. 2000).

The coexistence of ringwoodite and wadsleyite in the shock-induced melt vein here is particularly rare in other Martian meteorites and has only been reported in Chassigny (Fritz and Greshake 2009) and the poikilitic shergottite Asuka 12325 (Takenouchi et al. 2019). The ubiquity of ringwoodite and relative scarcity of wadsleyite in Martian meteorites may indicate that shock pressure in samples is generally well above the metastable olivine-ringwoodite equilibrium boundary (Fudge et al. 2014). In this case, olivine transforms directly to the ringwoodite over full range of transformation temperatures. The coexistence of ringwoodite and wadsleyite in the shock-induced melt vein of NWA 8705 may suggest that a lower formation pressure than that of other Martian meteorites (e.g., Miyahara et al. 2016, 2011; Wang et al. 2017). Additionally, the rare occurrences of the rod-like ringwoodite coexisting with the wadsleyite and the ringwoodite microlite clusters within the shock-induced melt veins in NWA8705 seem to imply a special crystallization process which may widen the understanding of the formation mechanism of ringwoodite.

\section{NWA 8705 impact history}

Shock-induced melt veins in NWA 8705 have recorded the P-T path after the impact event. The meteorite NWA 8705 was heated heterogeneously up to a temperature of $\sim 2000{ }^{\circ} \mathrm{C}$ at $\sim 18 \mathrm{GPa}$ (Fig. 10), producing the shockinduced melt during the shock event. The ringwoodite microlite clusters crystallized from the olivine-dominant melt at a condition of $16-18 \mathrm{GPa}$ and $\sim 1800{ }^{\circ} \mathrm{C}$. The association of the rod-like ringwoodite, wadsleyite, and pyroxene in the shock-induced melt veins quenched at slightly lower pressure (14-16 GPa) and temperature $\left(\sim 1700{ }^{\circ} \mathrm{C}\right)$.
The shock pressure duration of Martian meteorites was short and has been estimated to be $\sim 10 \mathrm{~ms}$ (Beck et al. 2005; Fritz and Greshake 2009; Ma et al. 2016), 10-20 ms (Walton et al. 2014; Walton 2013), and $100 \mathrm{~ms}$ (Sharp et al. 2019). The shock pressure duration estimated from NWA 8705 is $\sim 3.4-10 \mathrm{~ms}$, consistent with that of most other Martian meteorites. The impact scenario of NWA 8705 is probably similar with other shergottites, delivered from small craters $(1.5-5 \mathrm{~km}$ in diameter) (Beck et al. 2005; Artemieva and Ivanov 2004). It is generally suggested that Martian impact ejection events were small because of their young CRE ages, the decrease in size-frequency distribution of impact craters over the history of solar system, and that there are too few young large impact craters on Mars to account for all different ejection events (Head et al. 2002; Artemieva and Ivanov 2004). The cosmic ray exposure (CRE) age of NWA 8705 is $1.7 \mathrm{Ma}$ (Irving et al. 2017), which is young and similar to that of other olivine-phyric shergottites within error, e.g., CRE ages from 0.6 to $1.8 \mathrm{Ma}$ (Head et al. 2002; Nishiizumi et al. 2011; Eugster et al. 2006; Nyquist et al. 2001), suggesting that they may originate from the same small impact ejection event on Mars (Beck et al. 2005). In NWA 8705, the shock pressure 18 $\mathrm{GPa}$ estimated from the minerals assemblages within and adjacent to the shock-induced melt veins and pockets is lower compared with other olivine-phyric shergottites, e.g., $\geq 26-30 \mathrm{GPa}$ and 26-40 GPa for Tissint (Baziotis et al. 2013; Walton et al. 2014), 23 GPa for NWA 4468 (Boonsue and Spray, 2012), 23-25 GPa for NWA 6162 (El Goresy et al. 2013), > 25 GPa for DaG 735 (Miyahara et al. 2011). One reason may be that the lower pressure conditions in NWA 8075 estimated are for local hot spots rather than the peak shock conditions estimated based on the bulk shock metamorphism (Fritz et al. 2017). Another possibility is that its parent rock derived from regions outside the isobaric core (Gillet and El Goresy 2013; Fritz et al. 2017), and the mineral assemblages in shock-induced melt veins formed at a lower shock pressure.

\section{Conclusions}

NWA 8705 is an olivine-phyric shergottite with large olivine crystals in the finer-grained groundmass consisting mainly of pyroxene (pigeonite and augite) and interstitial maskelynite. There are four occurrences of ringwoodite: lamellae in the host olivine within or adjacent to shock-induced melt veins and pockets; polycrystalline ringwoodite olivine entrained in and adjacent to the shock-induced melt vein; rod-like ringwoodite coexisting with wadsleyite and pyroxene in the shock-induced melt vein matrix; the ringwoodite microlite clusters in a very 
thin shock-induced melt vein across the olivine. Based on their textures, TEM observations, and mineral compositions, polycrystalline ringwoodite and ringwoodite lamellae within the olivine adjacent to the shock-induced melt were produced via solid-state transformation, whereas the other two occurrences of ringwoodite in the shock-induced melt veins crystallized from the shockinduced melt.

The association of wadsleyite and ringwoodite in the matrix crystallized from the shock-induced melt vein limits the P-T parameters to $14-16 \mathrm{GPa}$ and 1650 $1750{ }^{\circ} \mathrm{C}$, respectively. The association of ringwoodite and glass in the melt vein constrains the crystallization pressure and temperature to 16-18 Gpa and 1750$1850{ }^{\circ} \mathrm{C}$, respectively. According to the $\mathrm{P}-\mathrm{T}$ conditions constrained from the mineral assemblages within and adjacent to the shock-induced melt veins and pockets, a shock pressure of $\sim 18 \mathrm{GPa}$ was estimated. The cooling times for the 20 and $60 \mu \mathrm{m}$ shock-induced melt veins are 0.4 and $3.6 \mathrm{~ms}$, respectively. The higher Facontents of the host olivine in NWA 8705 makes the olivine-ringwoodite transformation prolong to a lower pressure. The presence of four types of ringwoodite with two different formation mechanisms within a mmsized scale of the same meteorite was probably due to a very fast cooling rate and heterogenous temperature within and/or adjacent to shock-induced melt veins and pockets.

\begin{abstract}
Abbreviations
NWA: Northwest Africa; SEM: Scanning electron microscope; EDS: Energy-dispersive X-ray spectrometer; EPMA: Electron probe micro-analyzer; FIB: Focused ion beam; TEM: Transmission electron microscope; BSE: Backscattered electron; SAED: Selected area electron diffraction; HRTEM: High-resolution transmission electron microscope; BF-TEM: Bright-field transmission electron microscope; IGGCAS: Institute of Geology and Geophysics, Chinese Academy of Sciences; Rwt: Ringwoodite; Wad: Wadsleyite; SMP: Shock-induced melt pocket; px: Pyroxene; Cpx: Clinopyroxene; Gl: Glass; Ol: Olivine; Aug: Augite; Pig: Pigeonite; Msk: Maskelynite; Chr: Chromite; Ilm: Ilmenite; Sul: Sulfide; Mer: Merrillite; Ap: Apatite; Tr: Troilite; CRE: Cosmic ray exposure.
\end{abstract}

\section{Supplementary Information}

The online version contains supplementary material available at https://doi. org/10.1186/s40623-021-01494-1.

Additional file 1. Additional figures of NWA 8705.

Additional file 2. Additional tables of NWA 8705.

\section{Acknowledgements}

We are grateful to Yuan Xiao and Qin Zhou from the National Astronomical Observatories, Chinese Academy of Sciences, for their help in the Raman spectroscopy experiment. The authors also appreciate Lihui Jia and Di Zhang at the Institute of Geology and Geophysics, Chinese Academy of Sciences for their help in the EPMA experiments and Tao Wang at the Electron Microscopy Laboratory, Peking University for his efforts to maintain operation in TEM experiments.

\section{Authors' contributions}

TZ and YTL designed this study. SH supported sample preparations of NWA 8705. XT and LXG performed FIB-TEM analyses. TZ conducted the Raman, SEM, and EPMA analyses and interpreted analyzed all the experimental data. Under the supervisions of YTL, TZ finished the original manuscript. TZ, SH, NW, YTL, $X Y Z$, and $M M Z$ reviewed and edited the manuscript. This work was encouraged by YTL and NW. All the authors contributed to final manuscript. All the authors read and approved the final manuscript.

\section{Funding}

This research was funded by Beijing Municipal Science and Technology Commission, Grant Number Z191100004319001, and the Natural Science Foundation of China, Grant Number 41430105.

\section{Availability of data and materials}

The datasets in this study are available from the corresponding author on reasonable request.

\section{Declarations}

Ethics approval and consent to participate

Not applicable.

\section{Competing interests}

The authors declare that they have no competing interests.

\section{Author details}

${ }^{1}$ Key Laboratory of Earth and Planetary Physics, Institute of Geology and Geophysics, Chinese Academy of Sciences, Beijing 100029, China. ${ }^{2}$ University of Chinese Academy of Sciences, Beijing 100049, China. ${ }^{3}$ Electron Microscope Laboratory, Institute of Geology and Geophysics, Chinese Academy of Sciences, Beijing 100029, China. ${ }^{4}$ Key Laboratory of Mineral Resources, Institute of Geology and Geophysics, Chinese Academy of Sciences, Beijing 100029, China.

Received: 20 April 2021 Accepted: 11 August 2021

Published online: 24 August 2021

\section{References}

Acosta-Maeda TE, Scott ERD, Sharma SK, Misra AK (2013) The pressures and temperatures of meteorite impact: Evidence from micro-Raman mapping of mineral phases in the strongly shocked Taiban ordinary chondrite. Am Miner 98(5-6):859-869. https://doi.org/10.2138/am.2013.4300

Agee C, Li J, Shannon M, Circone S (1995) Pressure-temperature phase diagram for the Allende meteorite. J Geophys Res Solid Earth Solid Earth 100(B9):17725-17740. https://doi.org/10.1029/95JB00049

Artemieva N, Ivanov B (2004) Launch of Martian meteorites in oblique impacts. Icarus 1(171):84-101. https://doi.org/10.1016/j.icarus.2004.05.003

Asahara Y, Kubo T, Kondo T (2004) Phase relations of a carbonaceous chondrite at lower mantle conditions. Phys Earth Planet Inter 143-144:421-432. https://doi.org/10.1016/j.pepi.2003.10.011

Baziotis IP, Liu Y, DeCarli PS, Melosh HJ, McSween HY, Bodnar RJ, Taylor LA (2013) The Tissint Martian meteorite as evidence for the largest impact excavation. Nat Commun 4(1):1404. https://doi.org/10.1038/ncomm s2414

Baziotis I, Asimow PD, Hu J, Ferrière L, Ma C, Cernok A, Anand M, Topa D (2018) High pressure minerals in the Château-Renard (L6) ordinary chondrite: implications for collisions on its parent body. Sci Rep 8(1):9851. https:// doi.org/10.1038/s41598-018-28191-6

Beck P, Gillet P, Gautron L, Daniel I, El Goresy A (2004) A new natural highpressure $(\mathrm{Na}, \mathrm{Ca})$-hexaluminosilicate $[(\mathrm{CaxNa} 1-\mathrm{x}) \mathrm{Al} 3+\mathrm{xSi}-\mathrm{xO} 11]$ in shocked Martian meteorites. Earth Planet Sci Lett 219(1):1-12. https://doi. org/10.1016/S0012-821X(03)00695-2

Beck P, Gillet P, El Goresy A, Mostefaoui S (2005) Timescales of shock processes in chondritic and Martian meteorites. Nature 435(7045):1071-1074. https://doi.org/10.1038/nature03616 
Binns RA, Davis RJ, Reed SJB (1969) Ringwoodite, natural (Mg, Fe)2SiO4 spinel in the tenham meteorite. Nature 221(5184):943-944. https://doi.org/10. 1038/221943a0

Boonsue S, Spray J (2012) Shock-induced phase transformations in melt pockets within Martian meteorite NWA 4468. Spectrosc Lett 45(2):127-134. https://doi.org/10.1080/00387010.2011.614670

Chen M, Sharp TG, Goresy AE, Wopenka B, Xie X (1996) The majorite-pyrope + magnesiowüstite assemblage: constraints on the history of shock veins in chondrites. Science 271(5255):1570-1573. https://doi.org/10.1126/scien ce.271.5255.1570

Chen M, Ahmed EG, Philippe G (2004) Ringwoodite lamellae in olivine: clues to olivine-ringwoodite phase transition mechanisms in shocked meteorites and subducting slabs. Proc Natl Acad Sci USA 101(42):15033-15037. https://doi.org/10.1073/pnas.0405048101

Chen M, Li H, Goresy AE, Liu J, Xie X (2006) Fracture-related intracrystalline transformation of olivine to ringwoodite in the shocked Sixiangkou meteorite. Meteorit Planet Sci 41(5):731-737. https://doi.org/10.1111/j. 1945-5100.2006.tb00988.x

Chen M, Jing C, Xie X, Xu J (2007) A microstructural investigation of natural lamellar ringwoodite in olivine of the shocked Sixiangkou chondrite. Earth Planet Sci Lett 264(1-2):277-283. https://doi.org/10.1016/j.epsl. 2007.09.037

El Goresy A, Gillet P, Miyahara M, Ohtani E, Ozawa S, Lin Y, Feng L, Escerig S (2013) Multiple shock events and diamond formation on Mars. In: Abstracts of the 44th lunar and planetary science conference, Woodlands, TX, USA, 18-22 March 2013

Eugster O, Herzog G, Marti K, Caffee M (2006) Irradiation records, cosmicray exposure ages, and transfer times of meteorites. In: Lauretta DS, McSween HY (eds) Meteorites and the early solar system II, vol 1. University of Arizona Press, Tucson, pp 829-851

Feng L, Lin Y, Hu S, Xu L, Miao B (2011) Estimating compositions of natural ringwoodite in the heavily shocked Grove Mountains 052049 meteorite from Raman spectra. Am Miner 96(10):1480-1489. https://doi.org/10. 2138/am.2011.3679

Fritz J, Greshake A (2009) High-pressure phases in an ultramafic rock from Mars. Earth Planet Sci Lett 288(3):619-623. https://doi.org/10.1016/j.epsl. 2009.10.030

Fritz J, Artemieva N, Greshake A (2005) Ejection of Martian meteorites. Meteorit Planet Sci 40(9-10):1393-1411. https://doi.org/10.1111/j.1945-5100.2005. tb00409.x

Fritz J, Greshake A, Fernandes V (2017) Revising the shock classification of meteorites. Meteorit Planet Sci. https://doi.org/10.1111/maps.12845

Frost DJ (2008) The upper mantle and transition zone. Elements 4(3):171-176. https://doi.org/10.2113/gselements.4.3.171

Fudge C, Hu J, Sharp T (2014) The coexistence of wadsleyite and ringwoodite in L/LL Chondrite SAH 293: constraints on shock pressure conditions and olivine transformation. In: Abstracts of the 45th lunar and planetary science conference, Woodlands, TX, USA, 17-21 March 2014

Gillet P, El Goresy A (2013) Shock events in the solar system: the message from minerals in terrestrial planets and asteroids. Annu Rev Earth Planet Sci 41(1):257-285. https://doi.org/10.1146/annurev-earth-042711-105538

Gillet P, Chen M, Dubrovinsky L, El Goresy A (2000) Natural NaAlSi3O8-hollandite in the shocked Sixiangkou Meteorite. Science 287(5458):1633-1636. https://doi.org/10.1126/science.287.5458.1633

Greshake A, Fritz J, Böttger U, Goran D (2013) Shear-induced ringwoodite formation in the Martian shergottite Dar al Gani 670. Earth Planet Sci Lett 375:383-394. https://doi.org/10.1016/..epsl.2013.06.002

Gu L, Hu S, Anand M, Tang X, Ji J, Zhang B, Wang N, Lin Y (2022) Occurrence of tuite and ahrensite in Zagami and their significance for shock-histories recorded in Martian meteorites. Am Min. https://doi.org/10.2138/am2022-8020 (In press)

Head JN, Melosh HJ, Ivanov BA (2002) Martian meteorite launch: high-speed ejecta from small craters. Science 298:1752-1756

Hewins RH, Humayun M, Barrat JA, Zanda B, Lorand JP, Pont S, Assayag N, Cartigny P, Yang S, Sautter V (2020) Northwest Africa 8694, a ferroan chassignite: bridging the gap between nakhlites and chassignites. Geochim Cosmochim Acta 282:201-226. https://doi.org/10.1016/j.gca.2020.05.021

Hu J, Sharp TG (2016) High-pressure phases in shock-induced melt of the unique highly shocked LL6 chondrite Northwest Africa 757. Meteorit Planet Sci 51(7):1353-1369. https://doi.org/10.1111/maps.12672
Hu J, Sharp TG (2017) Back-transformation of high-pressure minerals in shocked chondrites: Low-pressure mineral evidence for strong shock. Geochim Cosmochim Acta 215:277-294. https://doi.org/10.1016/j.gca. 2017.07.018

Irving AJ, Kuehner SM, Lapen TJ, Righter M, Busemann H, Wieler R, Nishiizumi K (2017) Keeping up with the Martian meteorites and constraining the number of separate launch sites on Mars. In: Abstracts of the 48th lunar and planetary science conference, Woodlands, TX, USA, 20-24 March 2017

Ito E, Takahashi E (1989) Postspinel transformations in the system Mg2SiO4Fe2SiO4 and some geophysical implications. J Geophys Res Solid Earth Solid Earth 94(B8):10637-10646. https://doi.org/10.1029/JB094iB08p 10637

Katsura T, Ito $\mathrm{E}$ (1989) The system Mg2SiO4-Fe2SiO4 at high pressures and temperatures: precise determination of stabilities of olivine, modified spinel, and spinel. J Geophys Res Solid Earth Solid Earth 94(B11):15663-15670

Kerschhofer L, Sharp TG, Rubie DC (1996) Intracrystalline transformation of olivine to wadsleyite and ringwoodite under subduction zone conditions. Science 274(5284):79-81. https://doi.org/10.1126/science.274.5284.79

Kerschhofer L, Dupas C, Liu M, Sharp TG, Durham WB, Rubie DC (1998) Polymorphic transformations between olivine, wadsleyite and ringwoodite: mechanisms of intracrystalline nucleation and the role of elastic strain. Mineral Mag 62(5):617-638. https://doi.org/10.1 180/002646198548016

Kerschhofer L, Rubie D, Sharp T, McConnell J, Dupas-Bruzek C (2000) Kinetics of intracrystalline olivine-ringwoodite transformation. Phys Earth Planet Inter 121(1-2):59-76. https://doi.org/10.1016/S0031-9201(00)00160-6

Kleppe AK, Jephcoat AP, Smyth JR, Frost DJ (2002) On protons, iron and the high-pressure behavior of ringwoodite. Geophys Res Lett 29(21):171-174. https://doi.org/10.1029/2002GL015276

Langenhorst F, Poirier J-P (2000) Anatomy of black veins in Zagami: clues to the formation of high-pressure phases. Earth Planet Sci Lett 184(1):37-55. https://doi.org/10.1016/S0012-821X(00)00317-4

Liu M, Kerschhofer L, Mosenfelder JL, Rubie DC (1998) The effect of strain energy on growth rates during the olivine-spinel transformation and implications for olivine metastability in subducting slabs. J Geophys Res Solid Earth Solid Earth 103(B10):23897-23909. https://doi.org/10.1029/ 98jb00794

Ma C, Tschauner O, Beckett JR, Liu Y, Rossman GR, Sinogeikin SV, Smith JS, Taylor LA (2016) Ahrensite, $\gamma$-Fe2SiO4, a new shock-metamorphic mineral from the Tissint meteorite: Implications for the Tissint shock event on Mars. Geochim Cosmochim Acta 184:240-256. https://doi.org/10.1016/j. gca.2016.04.042

Martinez M, Brearley AJ, Trigo-Rodríguez JM, Llorca J (2019) New observations on high-pressure phases in a shock melt vein in the Villalbeto de la Peña meteorite: Insights into the shock behavior of diopside. Meteorit Planet Sci 54(11):2845-2863. https://doi.org/10.1111/maps.13391

McSween JY (1985) SNC meteorites: clues to Martian petrologic evolution? Rev Geophys 23(4):391-416. https://doi.org/10.1029/RG023i004p00391

Ming LC, Kim YH, Manghnani MH, Usha-Devi S, Xie HS (1991) Back transformation and oxidation of (Mg, Fe)2SiO4 spinels at high temperatures. Phys Chem Miner 18(3):171-179. https://doi.org/10.1007/BF00234000

Miyahara M, El Goresy A, Ohtani E, Nagase T, Nishijima M, Vashaei Z, Ferroir T, Gillet P, Dubrovinsky L, Simionovici A (2008) Evidence for fractional crystallization of wadsleyite and ringwoodite from olivine melts in chondrules entrained in shock-melt veins. Proc Natl Acad Sci USA 105(25):8542-8547. https://doi.org/10.1073/pnas.0801518105

Miyahara M, Goresy AE, Ohtani E, Kimura M, Ozawa S, Nagase T, Nishijima M (2009) Fractional crystallization of olivine melt inclusion in shock-induced chondritic melt vein. Phys Earth Planet Inter 177(3):116-121. https://doi. org/10.1016/j.pepi.2009.08.001

Miyahara M, Ohtani E, Kimura M, Goresy AE, Ozawa S, Nagase T, Nishijima M, Hiraga K (2010) Coherent and subsequent incoherent ringwoodite growth in olivine of shocked L6 chondrites. Earth Planet Sci Lett 295(1-2):321-327. https://doi.org/10.1016/j.epsl.2010.04.023

Miyahara M, Ohtani E, Ozawa S, Kimura M, El Goresy A, Sakai T, Nagase T, Hiraga K, Hirao N, Ohishi Y (2011) Natural dissociation of olivine to (Mg, $\mathrm{Fe}) \mathrm{SiO}<$ sub $>3</$ sub $>$ perovskite and magnesiowüstite in a shocked Martian meteorite. Proc Natl Acad Sci 108(15):5999-6003. https://doi.org/ 10.1073/pnas.1016921108 
Miyahara M, Ohtani E, El Goresy A, Ozawa S, Gillet P (2016) Phase transition processes of olivine in the shocked Martian meteorite Tissint: Clues to origin of ringwoodite-, bridgmanite- and magnesiowüstite-bearing assemblages. Phys Earth Planet Inter 259:18-28. https://doi.org/10.1016/j. pepi.2016.08.006

Mohiuddin A, Karato S-i, Girard J (2020) Slab weakening during the olivine to ringwoodite transition in the mantle. Nat Geosci 13(2):170-174. https:// doi.org/10.1038/s41561-019-0523-3

Mosenfelder JL, Marton FC, li CRR, Kerschhofer L, Rubie DC (2001) Experimental constraints on the depth of olivine metastability in subducting lithosphere. Phys Earth Planet Inter 127(1):165-180. https://doi.org/10. 1016/S0031-9201(01)00226-6

Nishiizumi K, Nagao K, Caffee MW, Jull A, Irving AJ, Nishiizumi K, Irving AJ (2011) Cosmic-ray exposure chronologies of depleted olivine-phyric shergottites. In: Abstracts of the 42nd lunar and planetary science conference, Woodlands, TX, USA, 7-11 March 2011

Nyquist LE, Bogard DD, Shih CY, Greshake A, Stöffler D, Eugster O (2001) Ages and geologic histories of Martian meteorites. Space Sci Rev 96(1):105164. https://doi.org/10.1023/A:1011993105172

Oguri K, Funamori N, Sakai F, Kondo T, Uchida T, Yagi T (1997) High-pressure and high-temperature phase relations in diopside CaMgSi2O6. Phys Earth Planet Inter 104(4):363-370. https://doi.org/10.1016/S0031-9201(97) 00029-0

Ohtani E, Sakai T (2008) Recent advances in the study of mantle phase transitions. Phys Earth Planet Inter 170(3-4):240-247. https://doi.org/10.1016/j. pepi.2008.07.024

Ohtani E, Kagawa N, Fujino K (1991) Stability of majorite (Mg, Fe)SiO3 at high pressures and $1800^{\circ} \mathrm{C}$. Earth Planet Sci Lett 102(2):158-166. https://doi. org/10.1016/0012-821X(91)90005-3

Ohtani E, Kimura Y, Kimura M, Takata T, Kondo T, Kubo T (2004) Formation of high-pressure minerals in shocked L6 chondrite Yamato 791384: constraints on shock conditions and parent body size. Earth Planet Sci Lett 227(3):505-515. https://doi.org/10.1016/j.epsl.2004.08.018

Ozawa S, Ohtani E, Miyahara M, Suzuki A, Kimura M, Ito Y (2010) Transformation textures, mechanisms of formation of high-pressure minerals in shock melt veins of L6 chondrites, and pressure-temperature conditions of the shock events. Meteorit Planet Sci 44(11):1771-1786. https://doi. org/10.1111/j.1945-5100.2009.tb01206.x

Pittarello L, Ji G, Yamaguchi A, Schryvers D, Debaille V, Claeys P (2015) From olivine to ringwoodite: a TEM study of a complex process. Meteorit Planet Sci 50(5):944-957. https://doi.org/10.1111/maps.12441

Presnall DC (1995) Phase diagrams of earth-forming minerals. In: Ahrens TJ (ed) Mineral physics and crystailography: a handbook of physical constants, vol 2. American Geophysical Union (AGU), Washington, pp 248-268

Putnis A, Price GD (1979) High-pressure (Mg, Fe)2SiO4 phases in the Tenham chondritic meteorite. Nature 280(5719):217-218. https://doi.org/10.1038/ $280217 \mathrm{a} 0$

Sarbadhikari AB, Babu EVSSK, Vijaya Kumar T, Chennaoui Aoudjehane H (2016) Martian meteorite Tissint records unique petrogenesis among the depleted shergottites. Meteorit Planet Sci 51(9):1588-1610. https://doi. org/10.1111/maps.12684

Sharp TG, De Carli PS (2006) Shock effects in meteorites. In: Lauretta DS, McSween HY (eds) Meteorites and the early solar system II. University of Arizona Press, Tucson, pp 653-677

Sharp TG, Walton EL, Hu J, Agee C (2019) Shock conditions recorded in NWA 8159 Martian augite basalt with implications for the impact cratering history on Mars. Geochim Cosmochim Acta 246:197-212. https://doi.org/ 10.1016/j.gca.2018.11.014

Stöffler D, Keil K (1991) Shock metamorphism of ordinary chondrites. Geochim Cosmochim Acta 55(12):3845-3867. https://doi.org/10.1016/00167037(91)90078-J

Suzuki I, Ohtani E, Kumazawa M (1980) Thermal expansion of modified spinel. J Phys Earth 28(3):273-280. https://doi.org/10.4294/jpe1952.28.273

Takenouchi A, Mikouchi T, Yamaguchi A (2018) Shock veins and brown olivine in Martian meteorites: Implications for their shock pressure-temperature histories. Meteorit Planet Sci 53(11):2259-2284. https://doi.org/10.1111/ maps.13120

Takenouchi A, Yamaguchi A, Mikouchi T (2019) Petrological study of Asuka 12325: the least shock-metamorphosed shergottite. Paper presented at the tenth symposium on polar science, National Institute of Polar Research, Japan, 5 December 2019

Tang X, Li QL, Zhang B, Wang P, Li JH (2020) The chemical state and occupancy of radiogenic $\mathrm{Pb}$, and crystallinity of $\mathrm{RW}-1$ monazite revealed by XPS and TEM. Minerals 10(6):504. https://doi.org/10.3390/min10060504

Tomioka N, Miyahara M (2017) High-pressure minerals in shocked meteorites. Meteorit Planet Sci 52(9):2017-2039. https://doi.org/10.1111/maps.12902

Treiman AH (2005) The nakhlite meteorites: Augite-rich igneous rocks from Mars. Geochemistry 65(3):203-270. https://doi.org/10.1016/j.chemer. 2005.01.004

Trønnes RG, Frost DJ (2002) Peridotite melting and mineral-melt partitioning of major and minor elements at 22-24.5 GPa. Earth Planet Sci Lett 197(1):117-131. https://doi.org/10.1016/S0012-821X(02)00466-1

Tschauner O (2014) Discovery of bridgmanite, the most abundant mineral in Earth, in a shocked meteorite. Science 346(6213):1100-1102. https://doi. org/10.1126/science.1259369

Walton EL (2013) Shock metamorphism of Elephant Moraine A79001: Implications for olivine-ringwoodite transformation and the complex thermal history of heavily shocked Martian meteorites. Geochim Cosmochim Acta 107:299-315. https://doi.org/10.1016/j.gca.2012.12.021

Walton EL, McCarthy S (2017) Mechanisms of ringwoodite formation in shocked meteorites: evidence from L5 chondrite Dhofar 1970. Meteorit Planet Sci 52(4):762-776. https://doi.org/10.1111/maps.12829

Walton EL, Sharp TG, Hu J, Filiberto J (2014) Heterogeneous mineral assemblages in Martian meteorite Tissint as a result of a recent small impact event on Mars. Geochim Cosmochim Acta 140:334-348. https://doi.org/ 10.1016/j.gca.2014.05.023

Wang SZ, Zhang AC, Pang RL, Chen JN, Wang RC (2017) Petrogenesis and shock metamorphism of the enriched Iherzolitic shergottite Northwest Africa 7755. Meteorit Planet Sci 52(11):3427-2457. https://doi.org/10. 1111/maps.12931

Weisberg MK, McCoy TJ, Krot AN (2006) Systematics and Evaluation of Meteorite Classification. In: Lauretta DS (ed) Meteorites and the early solar system II. University of Arizona Press, Tucson, pp 19-52

Xie Z, Sharp TG (2004) High-pressure phases in shock-induced melt veins of the Umbarger L6 chondrite: Constraints of shock pressure. Meteorit Planet Sci 39(12):2043-2054. https://doi.org/10.1111/j.1945-5100.2004. tb00095.x

Xie Z, Sharp TG (2007) Host rock solid-state transformation in a shock-induced melt vein of Tenham L6 chondrite. Earth Planet Sci Lett 254(3):433-445. https://doi.org/10.1016/j.epsl.2006.12.001

Xie X, Minitti ME, Chen M, Ho-k M, Wang D, Shu J, Fei Y (2002) Natural highpressure polymorph of merrillite in the shock veins of the Suizhou meteorite. Geochim Cosmochim Acta 66(13):2439-2444. https://doi.org/ 10.1016/S0016-7037(02)00833-5

Xie Z, Sharp TG, Decarli PS (2006a) High-pressure phases in a shock-induced melt vein of the Tenham L6 chondrite: constraints on shock pressure and duration. Geochim Cosmochim Acta 70(2):504-515. https://doi.org/10. 1016/j.gca.2005.09.003

Xie Z, Sharp TG, De Carli PS (2006b) Estimating shock pressures based on highpressure minerals in shock-induced melt veins of $L$ chondrites. Meteorit Planet Sci 41(12):1883-1898. https://doi.org/10.1111/j.1945-5100.2006. tb00458.x

Xie X, Sun Z, Chen M (2011) The distinct morphological and petrological features of shock melt veins in the Suizhou L6 chondrite. Meteorit Planet Sci 46(3):459-469. https://doi.org/10.1111/j.1945-5100.2011.01168.x

Yin F, Liao Z, Hursthouse A, Dai D (2018) Shock-induced olivine-ringwoodite transformation in the shock vein of chondrite GRV053584. Minerals 8(4):139. https://doi.org/10.3390/min8040139

Zhang J, Herzberg C (1994) Melting experiments on anhydrous peridotite KLB-1 from 5.0 to 22.5 GPa. J Geophys Res Solid Earth 99(B9):1772917742. https://doi.org/10.1029/94JB01406

\section{Publisher's Note}

Springer Nature remains neutral with regard to jurisdictional claims in published maps and institutional affiliations. 